\title{
Ni-perovskite interaction and its structural and catalytic consequences in methane steam reforming and methanation reactions
}

Ramona Thalinger ${ }^{1}$, Martin Gocyla ${ }^{2}$, Marc Heggen ${ }^{2}$, Rafal Dunin-Borkovski ${ }^{2}$, Matthias Grünbacher ${ }^{1}$, M. Stöger-Pollach ${ }^{3}$, Daniela Schmidmair ${ }^{4}$, Bernhard Klötzer ${ }^{1}$, Simon Penner ${ }^{1 *}$

${ }^{1}$ Institute of Physical Chemistry, University of Innsbruck, Innrain 80-82, A-6020 Innsbruck, Austria

${ }^{2}$ Ernst Ruska-Centrum und Peter Grünberg Institut, Forschungszentrum Jülich GmbH, 52425 Jülich, Germany

${ }^{3}$ University Service Centre for Transmission Electron Microscopy (USTEM), Vienna, University of Technology, Wiedner Hauptstrasse 8-10/052, A-1040, Vienna, Austria

${ }^{4}$ Institute of Mineralogy and Petrography, University of Innsbruck, Innrain 52d, A-6020 Innsbruck, Austria

Corresponding author: S. Penner, simon.penner@uibk.ac.at, Tel: +43 51250758003

Keywords: metal-support interaction, electron microscopy, lanthanum strontium ferrite (LSF), strontium titanium ferrite (STF), reduction, nickel-iron alloy, Ni-Fe alloy 


\begin{abstract}
Metal-support interaction effects and their consequences in $\mathrm{CO}_{2} / \mathrm{CO}$ methanation and methane steam reforming have been exemplarily studied on two complex Ni-perovskite powder catalyst systems, namely $\mathrm{Ni}-\mathrm{La}_{0.6} \mathrm{Sr}_{0.4} \mathrm{FeO}_{3-\delta}$ (lanthanum strontium ferrite, LSF) and $\mathrm{Ni}-\mathrm{SrTi}_{0.7} \mathrm{Fe}_{0.3} \mathrm{O}_{3-\delta}$ (strontium titanium ferrite, $\mathrm{STF}$ ). Pre-reduction in hydrogen and treatment in catalytic gas mixtures cause a variety of structural effects, including exsolution of iron particles and formation of Ni-Fe alloy particles. These manifestations strongly depend on the reducibility of the perovskite and are hence much more pronounced on LSF. Reactivity differences are strongly influenced by the chemical properties of the respective perovskite support. The more reducible the perovskite support, the stronger the deviation from the catalytic behaviour of a $\mathrm{Ni} / \mathrm{Al}_{2} \mathrm{O}_{3}$ reference catalyst, rendering establishments of direct structure-activity/selectivity relationships difficult. The studies show the extreme variety of the metal-perovskite interface, which helps in judging similar systems of recent high catalytic importance, e.g. metals supported on spinel or other perovskite phases.
\end{abstract}




\section{Introduction}

Perovskite materials have recently emerged as promising (electro-) catalytic materials with applications in a wide range of reactions, including oxidation reactions, pollution abatement, hydrogenation and hydrogenolysis, photo-catalysis or electro-catalysis [1,2]. The latter is usually connected either with oxygen reduction reactions or use as anode materials in SOFCs $[1,2]$. A particular interesting reaction, which has also been studied over different perovskite materials, is the methanation reaction from $\mathrm{CO}\left(\right.$ or $\left.\mathrm{CO}_{2}\right)$ and $\mathrm{H}_{2}$ to $\mathrm{CH}_{4}$ or its reverse reaction, the methane steam reforming reaction, respectively [3-15]. This also includes the dry reforming of methane [16]. Already known for over 100 years [17], especially the $\mathrm{CO}_{2}$ methanation reaction $\mathrm{CO}_{2}+4 \mathrm{H}_{2} \rightarrow \mathrm{CH}_{4}+2 \mathrm{H}_{2} \mathrm{O}$ has attracted recent interest due to the search for $\mathrm{CO}_{2}$ utilization in combination with energy-efficient storage solutions for renewable electricity. For the equivalent $\mathrm{CO}$ methanation reaction $\mathrm{CO}+3 \mathrm{H}_{2} \rightarrow \mathrm{CH}_{4}+\mathrm{H}_{2} \mathrm{O}$, this is linked to the generation of a natural gas substitute [3-5,7,12-14,18-20]. As a number of catalysts are active, including transition metals such as $\mathrm{Rh}, \mathrm{Ru}, \mathrm{Co}$ or $\mathrm{Ni}$, which potentially steer the selectivity patterns also to higher hydrocarbons or alcohols, the available literature on the methanation reaction is vast [3-5,7,12-14,18-21]. Comprehensive reviews on almost all aspects already exist [3-5]. This also holds for the methane steam reforming reaction, which is also a promising method for efficient hydrogen production [6]. The reason for the employment of perovskite materials in these reactions is multifold, but unfortunately does not come without drawbacks: this is basically due to their inherent structural and chemical complexity. Nevertheless, various perovskites, including $\mathrm{LaFeO}_{3}, \mathrm{LaNi}_{\mathrm{x}} \mathrm{Fe}_{1-\mathrm{x}} \mathrm{O}_{3}, \mathrm{LaNiO}_{3}$ or $\mathrm{La}_{1-\mathrm{x}} \mathrm{Ce}_{\mathrm{x}} \mathrm{Fe}_{0.7} \mathrm{Ni}_{0.3} \mathrm{O}_{3}$ have been found to especially exhibit a high activity in the steam reforming of methane with minimal coke deposition under low steam-to-carbon ratios [3-15]. Suppression of coke formation in the latter reaction is of particular importance, as the commonly employed $\mathrm{Ni}$ catalyst is especially prone to carbon deposition and subsequent coke formation. However, despite their obvious advantages, the necessarily high operating 
temperatures (e.g. $\mathrm{T} \geq 600{ }^{\circ} \mathrm{C}$ ) of both methanation and methane reforming reactions eventually induce irreversible structural changes, including structural collapse and exsolution of (reactive or inactive) metal particles from the perovskite lattice $[8,9-11,14,15]$. This has a very strong influence on the catalytic material under scrutiny, but at the same time is structurally very difficult to control. This is not always per se detrimental: for instance, exsolution of Fe from LSF has been shown to improve its water-splitting capability [22]. Taking this idea even further, alloying or even intermetallic compound formation following metal exsolution from supported metal-perovskite systems might lead to catalytically interesting systems. In close correlation to the formation of Ni-Fe alloy particles eventually following Fe exsolution observed on impregnated Ni-perovskite systems under scrutiny here, $\mathrm{Ni}_{3} \mathrm{Fe}$ intermetallic compounds or Ni-Fe alloy phases themselves already showed promising activity in methane and tar steam reforming $[23,24]$. Exsolution phenomena from perovskites are not uncommon and recently an elegant pathway of deliberately using their nonstoichiometry for generation of well-defined and dispersed metal particles by controlled exsolution has been reported [25-29]. These ideas must in principle be extended to the behavior of the perovskite systems in contact with the relevant reaction mixtures, which could again alter the structure obtained after activation treatments in situ. In that respect, detailed studies on the structure of perovskite systems after each step of activation and reaction have to be performed to gain a full picture of the structure-activity relationships in metal-on-complex oxide systems. Such studies have been already performed on the pure perovskite systems LSF and STF in (inverse) water gas shift reaction and methane oxidation and revealed significant differences in the extent of reduction and the reactivity of the respective lattice oxygen [30] and on metal-on- $\mathrm{LaFeO}_{3}$ systems, where the influence of the perimeter of the metalperovskite interface on catalytic proerpties has been highlighted [31,32]. 
In the present study, we extend these studies to an even more complex system, namely small Ni particles deliberately deposited by non-aqueous impregnation on STF (strontium titanium ferrite, $\mathrm{SrTi}_{0.7} \mathrm{Fe}_{0.3} \mathrm{O}_{3-\delta}$ ) and LSF (lanthanum strontium ferrite, $\mathrm{La}_{0.6} \mathrm{Sr}_{0.4} \mathrm{FeO}_{3-\delta}$ ) perovskite supports. The reason to study such systems is multifold: addition of Ni eventually leads to hydrogen activation and possibly also to different pathways of perovskite structural changes during activation and reaction. Secondly, the deliberate addition of Ni should in principle help to create an improved methanation/methane reforming perovskite catalyst. Thirdly, which provides the connecting link to electro-catalysis and SOFC-research, impregnated catalyst systems with a lower Ni loading should in principle be favored over the so far used cermet anode materials. Cermet materials with percolated and sintered Ni bulk morphologies provide a lower surface area/electro-catalytic interface compared to smaller Ni particles. Furthermore, impregnation techniques are standard routines in catalyst preparation. The latter, however, poses additional problems: since especially LSF is suspected to become hydrolyzed under aqueous conditions [33], water-free alternatives in preparation are to be preferred, but at the same time are not straightforward. Here, we have chosen a preparation pathway using Ni(II)acetylacetonate as catalyst precursor material. As shown below, this reproducibly creates NiLSF and Ni-STF catalysts with well-defined and dispersed Ni particles. In due course, these systems are perfect candidates to study the structural interaction and catalytic consequences of metal-perovskite interaction. Apart from catalytic measurements, dedicated electron microscopy techniques are used to establish the anticipated structure-activity correlations. As a result, the direct comparison of Ni-LSF and Ni-STF will reveal the different structural consequences of perovskite reducibility, associated metal exsolution and metal-perovskite interaction, also in correlation to a $\mathrm{Ni}-\mathrm{Al}_{2} \mathrm{O}_{3}$ reference catalyst.

\section{Experimental}




\subsection{Materials preparation}

Synthesis of pure LSF and STF has been discussed in detail in ref. [30]. The Pechini route was used to synthesize $\mathrm{La}_{0.6} \mathrm{Sr}_{0.4} \mathrm{FeO}_{3-\delta}$ [34]. In case of the $\mathrm{SrTi}_{0.7} \mathrm{Fe}_{0.3} \mathrm{O}_{3-\delta}$ a solid state reaction was performed [30]. As for the preparation of the Ni-LSF and Ni-STF samples (10 mol\% of $\mathrm{Ni}$ ), a synthesis routine avoiding water-containing solutions has been followed. Aqueous impregnation especially on LSF potentially may lead to alkaline oxide hydrolysis (e.g. $\mathrm{La}_{2} \mathrm{O}_{3}$ or $\mathrm{SrO}$ ) [33]. Therefore, a solution of $\mathrm{Ni}$-acetylacetonate $\left(\mathrm{Ni}(\mathrm{acac})_{2}\right)$ has been used as $\mathrm{Ni}$ precursor material. $\mathrm{Ni}(\mathrm{acac})_{2}$ was dissolved in $30 \mathrm{~mL}$ acetone and subsequently, a suspension with $1 \mathrm{~g}$ perovskite material prepared. The resulting solution was vigorously stirred for $30 \mathrm{~min}$, dried in air and finally calcined in pure oxygen at $600{ }^{\circ} \mathrm{C}$ for $2 \mathrm{~h}$. Afterwards, the structural integrity of the perovskite and the presence of $\mathrm{NiO}$ was verified by XRD (Figure 1). Hence, the starting state of both materials is NiO-LSF and NiO-STF. Surface areas using the BET method were determined for both samples to be around $0.4 \mathrm{~m}^{2} \mathrm{~g}^{-1}$. BET surface areas were measured with a Quantachrome Nova 2000 Surface and Pore Size Analyser. The $\mathrm{Ni} / \mathrm{Al}_{2} \mathrm{O}_{3}$ reference catalyst was prepared by initial co-precipitation of $\mathrm{Ni}$ and boehmite $(\mathrm{AlOOH})$, closely following a routine outlined in detail in ref. [35]. All the structural details except the catalytic data can be found in the Supporting Information. The reference catalyst was subjected to pre-oxidation $\left(\mathrm{O}_{2}, 400{ }^{\circ} \mathrm{C}, 1 \mathrm{~h}\right)$ and pre-reduction $\left(\mathrm{H}_{2}, 600\right.$ ${ }^{\circ} \mathrm{C}, 1 \mathrm{~h}$ ) prior to catalytic testing.

\subsection{Pre-treatments and catalytic experiments}

All catalytic measurements discussed below are carried out in a $13 \mathrm{~mL}$ re-circulating quartz batch reactor constructed for $\sim 100 \mathrm{mg}$ catalyst. Details of the setup are given in [30]. The gas phase composition is detected online using a quadrupole mass spectrometer, connected via a capillary to the reactor. Before each experiment, a pre-treatment routine consisting of an oxidative and reductive treatment is performed. Firstly, the catalyst is calcined at $400{ }^{\circ} \mathrm{C}$ and 
isothermally treated for $1 \mathrm{~h}$ in oxygen to remove carbonaceous surface contaminations. During this process, $\mathrm{Ni}$ is oxidized - therefore, the catalyst is subsequently treated in hydrogen for $1 \mathrm{~h}$ at $600{ }^{\circ} \mathrm{C}$. This transforms the catalysts into metallic Ni particles both on LSF and STF and leads to controlled reduction of the support without decomposition of the perovskites [30]. Subsequently, the gas mixtures for the respective reactions were dosed at $100{ }^{\circ} \mathrm{C}$ and the reactor heated with $5{ }^{\circ} \mathrm{C} \min ^{-1}$ up to a final temperature of $600{ }^{\circ} \mathrm{C}$.

For analysis of the catalytic turnover, the relative intensities of the mass spectrometer signals were at first converted into partial pressures via external calibration using gas mixtures of defined partial pressures, and given in $\operatorname{mbar} \min ^{-1}$ vs. time (cf. Supporting Information Figures S6 and S7). Correction for the steady removal of a fraction of the reaction mixture through the capillary leak has been achieved by adding 10 mbar inert gas (Ar) at the beginning of the reaction and in-parallel monitoring the $\mathrm{m} / \mathrm{z}=40$ intensity throughout the whole experiment. Accounts of mass and heat transport limitations in the chosen reactor setup have been thoroughly assessed in a previous publication [30] and at this point, only a brief calculation should be given to show that mass transport limitation does not play a substantial role under the chosen reaction conditions. Comparing the collision number $\mathrm{Z}$ (derived from $\mathrm{Z}$ $\left.=\mathrm{p} /(2 \pi \mathrm{mkT})^{1 / 2} ; \sim 10^{21} \mathrm{sec}^{-1} \mathrm{~cm}^{-2}\right)$ with the maximum $\mathrm{CH}_{4}$ TOF value per $\mathrm{cm}^{-2}$ on Ni-STF $\left(\sim 6 \times 10^{11} \mathrm{sec}^{-1} \mathrm{~cm}^{-2}\right)$, it is clear that mass transport is not a limiting factor. Pore diffusion is also excluded due to the low surface areas of the catalysts under question $\left(\sim 0.4 \mathrm{~m}^{2} \mathrm{~g}^{-1}\right.$, see section 2.1). Heat transfer limitation is also thought to play a minor role since the low reaction rates suppress local temperature gradients and generally, heat transfer via the gas phase is limited due to the admission of He to all reaction mixtures.

To follow the methanation reaction, two different reactions starting from either $\mathrm{CO}_{2}$ or $\mathrm{CO}$ were investigated:

$$
\mathrm{CO}_{2}+4 \mathrm{H}_{2} \rightarrow \mathrm{CH}_{4}+2 \mathrm{H}_{2} \mathrm{O}
$$




$$
\mathrm{CO}+3 \mathrm{H}_{2} \rightarrow \mathrm{CH}_{4}+\mathrm{H}_{2} \mathrm{O}
$$

For reaction (1), 20 mbar $\mathrm{CO}_{2}, 80 \mathrm{mbar}_{2}$, (and $25 \mathrm{mbar} \mathrm{H}_{2} \mathrm{O}$ in order to provide a constant partial pressure value of water throughout the experiment) were used to perform the reaction. In contrast, 20 mbar $\mathrm{CO}$ and 60 mbar $\mathrm{H}_{2}$ were used for reaction (2). The reverse reaction, methane steam reforming,

$$
\mathrm{CH}_{4}+x \mathrm{H}_{2} \mathrm{O} \rightarrow \mathrm{CO}_{x}+(2+x) \mathrm{H}_{2}
$$

was performed using 25 mbar $\mathrm{H}_{2} \mathrm{O}$ and $25 \mathrm{mbar}^{\mathrm{CH}_{4}}$. In all cases, $\mathrm{He}$ was added to 1 bar total pressure for improved heat transfer and re-circulation efficiency.

To determine the turnover frequencies (TOF values) normalized to the number of surface $\mathrm{Ni}$ sites and to ensure a direct comparison of the activity of the catalysts, the following routine has been followed: as a first step, the average Ni particle diameter has been determined from several transmission electron microscopy (TEM) images to be $\sim 25 \mathrm{~nm}$ for $\mathrm{Ni}$ on LSF and STF, respectively (cf. Figure 1). The total Ni volume (with $10 \mathrm{~mol} \% \mathrm{Ni}$ ) then amounts to $1.73 \times 10^{-10} \mathrm{~m}^{3}$ and $4.79 \times 10^{-10} \mathrm{~m}^{3}$ for $\mathrm{Ni}$ on $\mathrm{LSF}$ and $\mathrm{STF}$, respectively. As a simple approximation, which is supported by TEM (cf. Figure 2), we assume a half-sphere shape of the Ni particles (note that this is only a rough, but justified approximation. Although some particles, especially after catalysis rather exhibit a "3/4-sphere shape", the differences in calculated TOF values are marginal). Using the volume of one Ni half-sphere particle as derived from the average particle diameter in TEM images, the number of Ni particles is determined to be $1.34 \times 10^{14}$ and $7.5 \times 10^{13}$ for Ni on LSF and STF, respectively. Considering the surface of the half-sphere (without interface to the support) and multiplying this by the number of particles yields the total accessible Ni surface: $0.0611 \mathrm{~m}^{2}$ on LSF and $0.099 \mathrm{~m}^{2}$ on STF. Using the average number of Ni atoms per $\mathrm{m}^{2}$ metal surface $\left(2.0 \times 10^{19}\right)$, the final number of accessible Ni atom sites was estimated to be $1.24 \times 10^{18}$ and $2.01 \times 10^{18}$ on Ni-LSF and Ni- 
STF, respectively. The same procedure has been performed on the $\mathrm{Ni} / \mathrm{Al}_{2} \mathrm{O}_{3}$ catalyst for the most direct comparison of the structure-activity correlations and results, according to TEM analysis, to $9.8 \times 10^{17} \mathrm{Ni}$ atom sites. Note that apart from the half-sphere assumption, two more approximations are the basis of TEM analysis: firstly, the extent of alloying is deliberately neglected and secondly, all $\mathrm{Ni}$ atoms are assumed to be active sites. Hence, the calculated TOF values represent the upper limit, but anyway serve as values for a comparative discussion.

To indirectly validate the TEM measurements, the calculated accessible Ni sites, and hence the apparent activation energies and the resulting TOF values, have been also determined by additional hydrogen and $\mathrm{CO}$ chemisorption measurements at room temperature. Before these measurements, the catalysts were oxidized $\left(400^{\circ} \mathrm{C}, \mathrm{O}_{2}, 1\right.$ bar $)$ and pre-reduced $\left(600^{\circ} \mathrm{C}, \mathrm{H}_{2}, 1\right.$ h). Hydrogen was subsequently removed by temperature-programmed desorption up to $600^{\circ} \mathrm{C}$. While the hydrogen chemisorption measurements are too affected by interaction with the perovskite blurring the adsorption on the metal surface, the corresponding $\mathrm{CO}$ adsorption experiments (although the same limitation of perovskite reduction by $\mathrm{CO}$ in principle applies) validate the TEM calculations. Table 1 summarizes these data. Experimentally, CO has been stepwise added at room temperature under static conditions until quasi-saturation has been observed. The corresponding data are shown in the SI (Figure S3). Note, as stated above, that spill-over effects impede a clear saturation. Langmuir fits have been applied and used for calculation of the amount of adsorbed $\mathrm{CO}$, the number of active sites and the TOF values. The accuracy of the analysis is revealed by the good agreement between TEM and adsorption studies.

The apparent activation energies for the $\mathrm{CO}_{2}$ methanation reaction are calculated on the basis of an Arrhenius fit to the TOF vs. reaction temperature graphs, both derived from the TEM 
results and the $\mathrm{CO}$ chemisorption measurements and for all three catalysts. The fits are highlighted in the SI (Figure S4), the derived data jointly shown in Table 1.

\subsection{Structural Characterization}

For the TEM measurements, all samples were suspended in acetone, treated in an ultrasonic bath and transferred to a holey carbon film on a copper grid. Before each measurement, the samples were dried by heating in vacuum for $12 \mathrm{~h}$ at $80{ }^{\circ} \mathrm{C}$. Microscopic characterisation was performed with four different transmission electron microscopes: A FEI Tecnai G2 F20 (acceleration voltage of $200 \mathrm{kV}$ ) was used for overview as well as high resolution imaging and energy-dispersive X-ray (EDX) spectroscopy overview maps. A spherical-aberration (Cs) image-corrected FEI Titan microscope operated at $300 \mathrm{kV}$ was used for high resolution imaging. Two Cs-probe corrected FEI Titan scanning transmission electron microscopes were used for electron energy loss spectroscopy (EELS) and EDX spectroscopy. One is equipped with a Gatan image filter (GIF) Tridiem 866ERS and the other one with four large-solid-angle symmetrical Si drift detectors (Super-X detector, FEI ChemiSTEM). "Z-Contrast” images were obtained using a high-angle annular dark field (HAADF) detector, a probe semi-angle of $25 \mathrm{mrad}$, and inner collection semi angles of the detector of 70 and $88 \mathrm{mrad}$, respectively. All XR diffractograms were collected with a Bruker AXS D8-Advance powder diffractometer. The samples were prepared on a rotatable Si single crystal to minimize background signals. The range of measurement was chosen from $2 \theta=20$ to $90^{\circ}$ with a step size of $0.02^{\circ}$.

\section{Results and Discussion}

\subsection{Structural Characterization}

Figure 1 shows a set of XR diffractograms, highlighting Ni-STF and Ni-LSF in the as-grown state (b and e) and after the $\mathrm{CO}_{2}$ methanation reaction (c and $\mathrm{f}$ ), in comparison to pure STF (a) and LSF (d). The structural stability of the respective perovskites and changes upon 
reductive/oxidative treatments (peak-shifts and -broadening due to changing amount of lattice oxygen, see Figure 1) are discussed elsewhere [30]. The theoretically calculated diffractograms of STF (04-013-9876) [36], LSF (01-072-8136) [37], NiO (00-047-1049, blue) [38] and Ni (00-001-1260, green) [39] taken from the ICDD PDF4+ database are shown on the bottom of Figure 1. After impregnation and calcination of the catalysts small $\mathrm{NiO}$ peaks are visible. These signals change into those of $\mathrm{Ni}$ after the catalytic measurements. Hence, for LSF and STF the perovskite lattice as a structural entity is preserved also in presence of metallic Ni particles and after the impregnation routine.

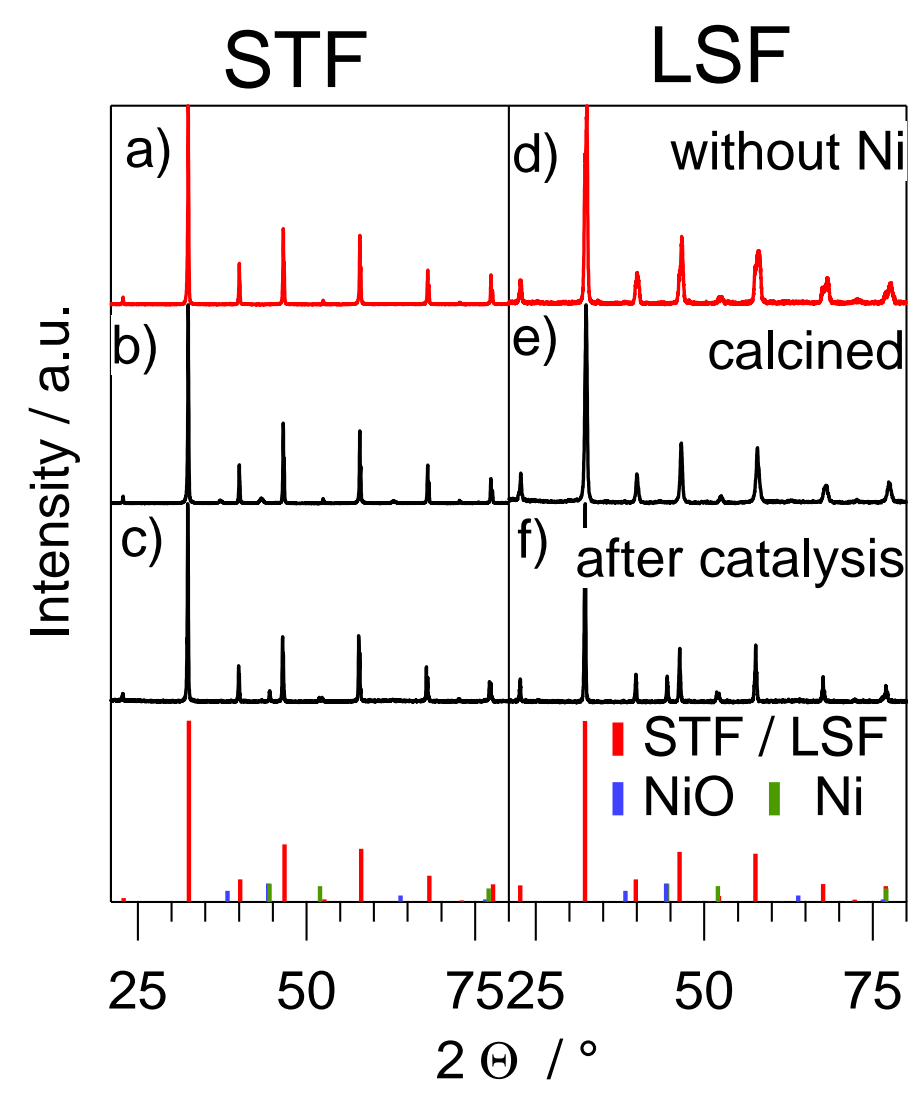

Figure 1: Representative X-ray diffractograms of pure STF (a), pure LSF (d), calcined impregnated Ni-STF (b), Ni-LSF (e) and both catalysts after reductive activation at $600{ }^{\circ} \mathrm{C}$ followed by a catalytic $\mathrm{CO}_{2}$ methanation reaction up to $600{ }^{\circ} \mathrm{C}$ (c and f), respectively. The bottom panels show the theoretical diffractograms of STF, LSF (red), NiO (blue) and Ni 
(green) on the basis of the ICDD PDF4+ database, patterns 04-013-9876 (STF) [36], 01-0728136 (LSF) [37], 00-047-1049 (NiO) [38] and 00-001-1260 (Ni) [39].

As an outlook to the structural changes discussed below, we note that although the LSF perovskite structure is stable, the overall structure of the catalyst appears to be much more complex and additionally consists of exsolved iron particles and Ni-Fe alloy particles, which do not show up in the XR diffractograms.

Figure 2 reveals the structure of the initial Ni-STF (panel A) and Ni-LSF (panel B) materials. Both overview TEM images (main panels) show an array of more or less irregularly-shaped particles of about 10-30 nm size. Most of these particles exhibit a characteristic core-shell structure, consisting of a hollow core. This structure is very characteristic for $\mathrm{NiO}$ particles prone to the Kirkendall effect [40]. Such hollow particles can be best seen in the insets denoted by " 1 " in both panels. A1 is therefore highlighting an EDX map of a single NiO particle. For Ni-LSF, an EELS map and the corresponding HAADF image are shown (B1). Inset "2" in Panel A in addition shows an EELS map of a NiO particle without pronounced core-shell structure (the oxygen O-K edge intensity is shown in red; the left side of the inset shows a superposition of Ni-L (green), O-K and Fe-L (blue) edges). In view of a detailed determination of the catalytic turnover, the dispersion and mean particle size have been calculated by particle statistics based on analysis of about 100 particles. The results are highlighted as histograms as additional insets in the respective upper right corners. For NiSTF, a broader size distribution as compared to Ni-LSF has been observed with an apparent second maximum for particle sizes around $50 \mathrm{~nm}$. However, as the respective particle size distribution after catalytic treatment (for the methane reforming reaction, Figure S5) on NiSTF does not show this peculiar maximum, it is considered a side effect of data evaluation. More importantly, the mean particle sizes for all catalysts do not change significantly 
(meaning that considerable particle sintering is absent) and amounts for both perovskite systems to $\sim 25 \mathrm{~nm}$. This value is then used for site calculation.
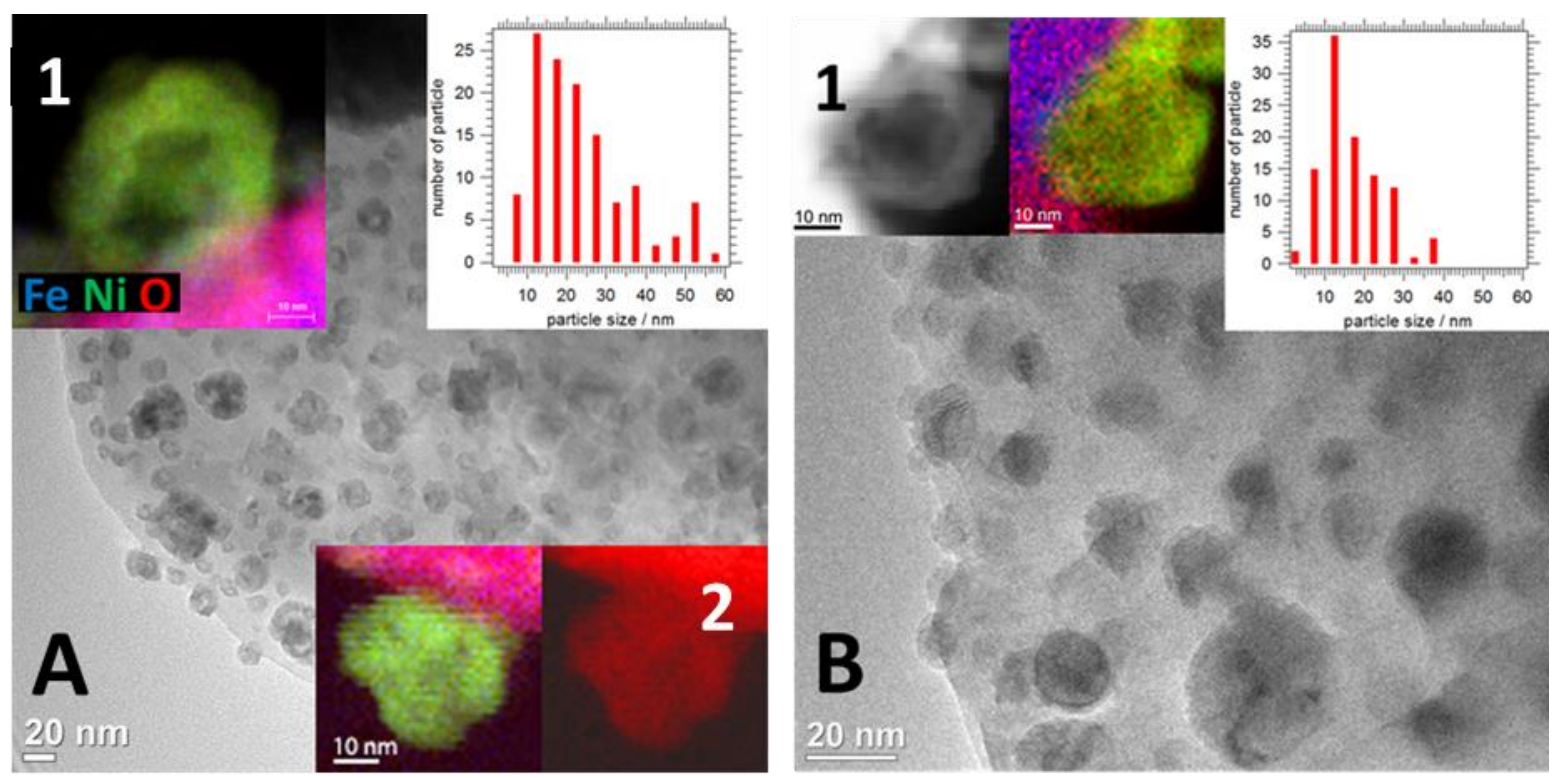

Figure 2: Overview TEM images of Ni-STF (panel A), Ni-LSF (panel B) and their particle size distributions (right upper insets). EDX (A1), EELS Maps (A2, B1 right) and HAADF image (B1 left) of hollow $\mathrm{NiO}$ on the respective perovskites. The $\mathrm{O}-\mathrm{K}$ edge intensity is shown in red, the Fe-L intensity in blue and the Ni-L intensity in green.

In order to test the catalytic behavior of the prepared Ni-STF and Ni-LSF materials in comparison to an already well-characterized $\mathrm{Ni}-\mathrm{Al}_{2} \mathrm{O}_{3}$ catalyst [41-43], Figure $\mathrm{S} 1$ shows the structure and morphology of a $\mathrm{Ni}-\mathrm{Al}_{2} \mathrm{O}_{3}$ reference catalyst in the as-prepared state. Subsequently, the stability of both Ni-perovskite systems was tested under reductive and reaction conditions up to $600{ }^{\circ} \mathrm{C}$. Both samples were tested under static re-circulating conditions to ensure direct comparison between reduction in hydrogen and catalytic treatment in the methane steam reforming mixture. Figure 3 highlights an overview TEM image of the state of Ni-STF after static reduction. A considerable number of Ni particles still appears dispersed on a large STF grain and the particle size histogram (upper right panel) indicates that sintering is largely absent: the mean particle size still is in the range of $25 \mathrm{~nm}$. The 
corresponding high-resolution image shows a $\mathrm{Ni} / \mathrm{NiO}$ core shell particle (the corresponding $\mathrm{Ni}$ (200) and $\mathrm{NiO}$ (111) lattice planes have been color-coded in blue and green to enhance visibility). The $\mathrm{NiO}$ shell most probably is formed during transport to the microscope. On NiSTF, these are the only structural features that are observed after reduction.

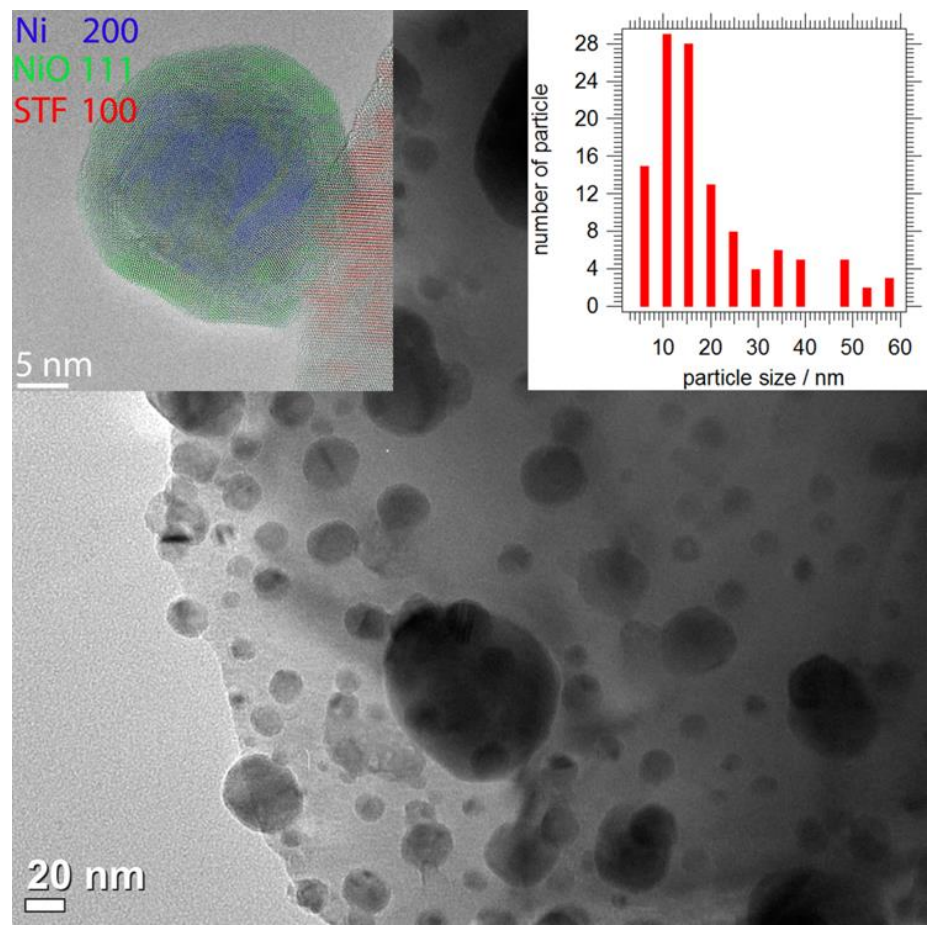

Figure 3: Overview TEM image of Ni-STF after static reduction at $600{ }^{\circ} \mathrm{C}$ in $1 \mathrm{bar}_{2}$ for $1 \mathrm{~h}$ (main panel), the corresponding particle size distribution (right inset) and a color-coded highresolution TEM image of a core shell $\mathrm{Ni} / \mathrm{NiO}$ particle (left inset).

In contrast, due to the higher iron content of LSF, on the corresponding Ni-LSF sample the structural situation after reduction is much more complex: Although still $\mathrm{Ni} / \mathrm{NiO}$ particles are observed (Figure 4, left panel), the EELS maps (right panel of Figure 4) indicates partial alloying of $\mathrm{Ni}$ (green) and $\mathrm{Fe}$ (blue). Such a single Ni-Fe particle is shown. Its elemental distribution indicates that iron is more or less equally distributed within the alloy particle (lower right corner, blue colored Fe-L edge). Oxygen (red colored; O-K edge intensity) is mainly found at the particle edges, indicating predominant surface oxidation. In fact, the large EELS map in the upper panel is an overlay of three individual Ni-L (green colored), Fe-L and 
$\mathrm{O}-\mathrm{K}$ intensities, revealing the intermixing of $\mathrm{Ni}$ and $\mathrm{Fe}$. This is in in agreement with studies of Urusaki et al. on $\mathrm{Ni}-\mathrm{LaFeO}_{3}$ and $\mathrm{Ni}-\mathrm{SrTiO}_{3}$ catalysts [15], who also observed that the former, due to the increased iron content, is inherently structurally less stable than $\mathrm{Ni}-\mathrm{SrTiO}_{3}$.

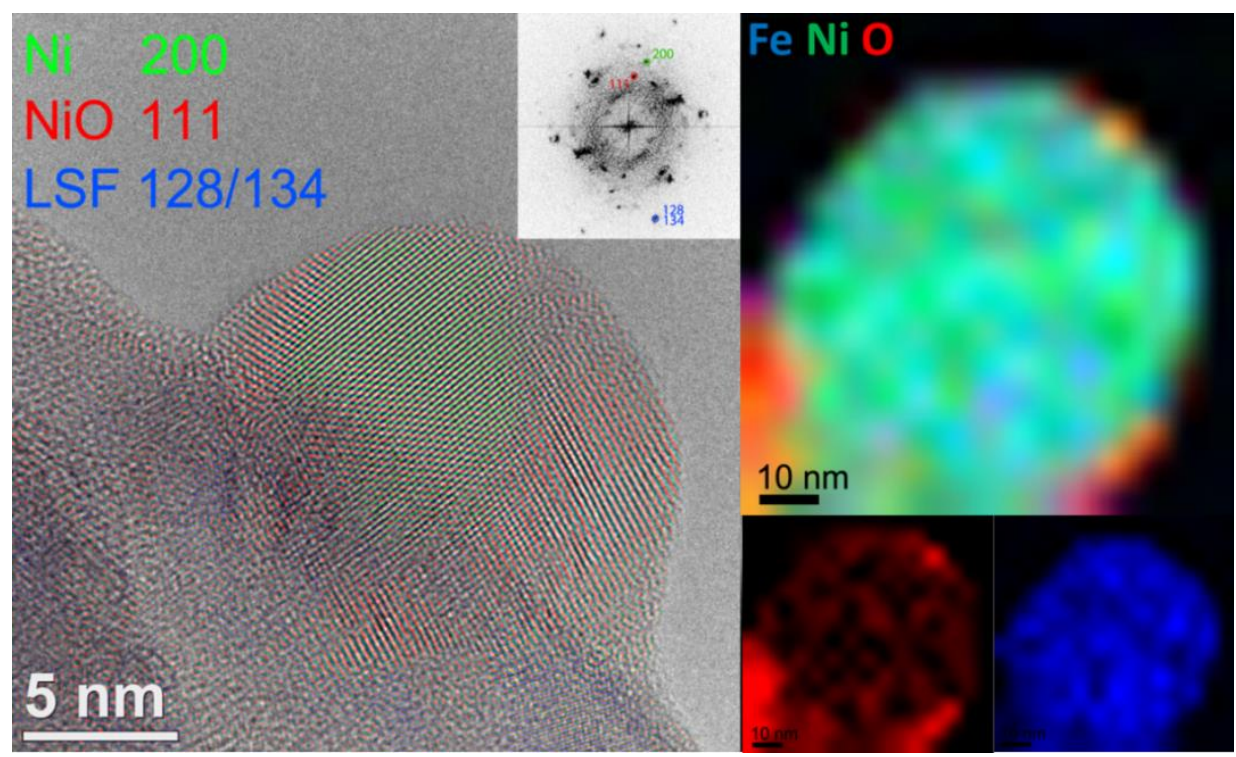

Figure 4: Left panel: HRTEM image of a core-shell Ni/NiO particle on Ni-LSF after static reduction in $\mathrm{H}_{2}$ at $600{ }^{\circ} \mathrm{C}$ (conditions as in Figure 3). Right panel: EELS maps of a single NiFe containing particle (above: superposition of Ni-L (green), O-K (red) and Fe-L (blue) edge intensity; below: individual O-K (red) and Fe-L (blue) maps of the same particle).

In due course, the question how the structure of both pre-reduced Ni-STF and Ni-LSF changes upon contact to the methane steam reforming reaction mixture is answered, as for pure LSF and STF, the changes introduced after reduction were found to be partially reversed on LSF upon contact to the reaction mixture, but, in contrast, the pre-reduced structure of STF remains largely unchanged [30]. Figure 5, highlighting HRTEM images and EDX maps of NiSTF, directly reveal that further contact to the methane steam reforming mixture after reduction does not induce further structural changes. The HRTEM image shows a single metallic Ni particle in [111] orientation, as derived from the FFT taken from the red-squared region. Additionally, the green-squared region reveals the atom-level unchanged structure of 
STF. Corroborating these findings, the respective EDX maps in Panel B show an array of chemically largely unchanged metallic Ni particles (green-colored Ni-L intensity, main panel and inset in the upper right corner). Note that especially in the main panel a thin shell of $\mathrm{NiO}$ arising from surface oxidation can be seen. More important and best visible in the upper left inset highlighting the Ni-STF interface, is the very small extent of Ni-Fe intermixing directly at the interface. The level of intermixing does only extend about $2 \mathrm{~nm}$ into the Ni particle, indicating only a small structural and electronic distortion of the Ni lattice. It is expected, that these effects are much more pronounced in the case of LSF, due to its more pronounced reducibility.

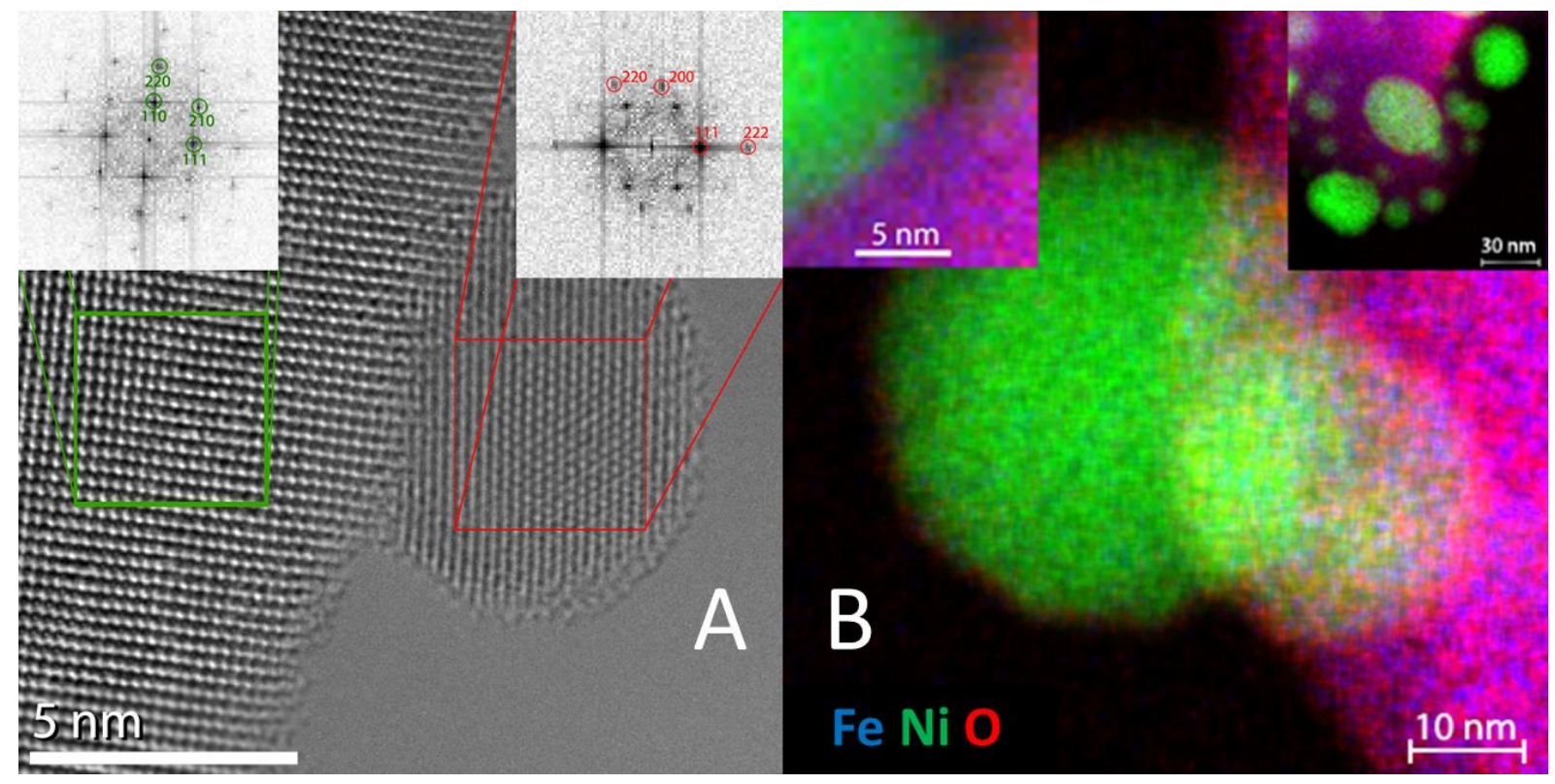

Figure 5: HRTEM image of a single Ni particle on STF after the catalytic methane steam reforming reaction at a maximum temperature of $600{ }^{\circ} \mathrm{C}$ (panel A) and corresponding EDX maps of an array of Ni particles on STF (main panel B and upper right inset). An EELS map of the Ni-STF interface is shown as left upper inset.

As direct proof of this assumption, Figure 6 and 7 show the corresponding experiments on NiLSF. In Figure 6, both the HRTEM image (main panel) and the EELS map (left inset) reveal the high level of Ni-Fe intermixing and the subsequent formation of a $\mathrm{Ni}-\mathrm{Fe}$ alloy. Fe appears 
surface-oxidized in Figure 6 (blue-colored $\mathrm{Fe}_{2} \mathrm{O}_{3}(024)$ lattice spacings). Also in the EELS map of the single particle the superposition of Fe-L (blue) and Ni-L (green) intensities suggest considerable alloy formation.

The current findings already indicate that the catalyst entity after reduction and catalysis represents a structurally very complex state. In order to focus on the eventual influence of alloy formation on the catalytic properties and to detect a potential particle size dependence of alloy formation, 28 particles in the particle size range between 10 and $90 \mathrm{~nm}$ have been analyzed regarding their $\mathrm{Fe} / \mathrm{Ni}$ ratio, i.e. the extent of alloy formation (this analysis has been restricted to the LSF case, since for STF the extent of alloy formation is too suppressed for reliable interpretation). In short, a characteristic ratio of $\sim 0.2$ results for all particle sizes, implying that alloy formation is at least not strongly particle-size dependent. The catalytic consequences are discussed in section 3.2.

These findings are further confirmed by the EDX maps shown in Figure 7. Panel A shows a single Ni-Fe alloy particle and panel B a larger-scale EDX map of an array of distributed pure $\mathrm{Ni}$ and Ni-Fe alloy particles. As a further manifestation of Ni-LSF interaction, panel $\mathrm{C}$ additionally shows an exsolved Fe particle attached to a larger LSF grain (with surfaceoxidation especially pronounced in the upper right corner). Such effects are exclusively observed on LSF due to the easier reducibility [30], giving rise to more pronounced extent of Ni-LSF interaction and hence Fe exsolution effects. 


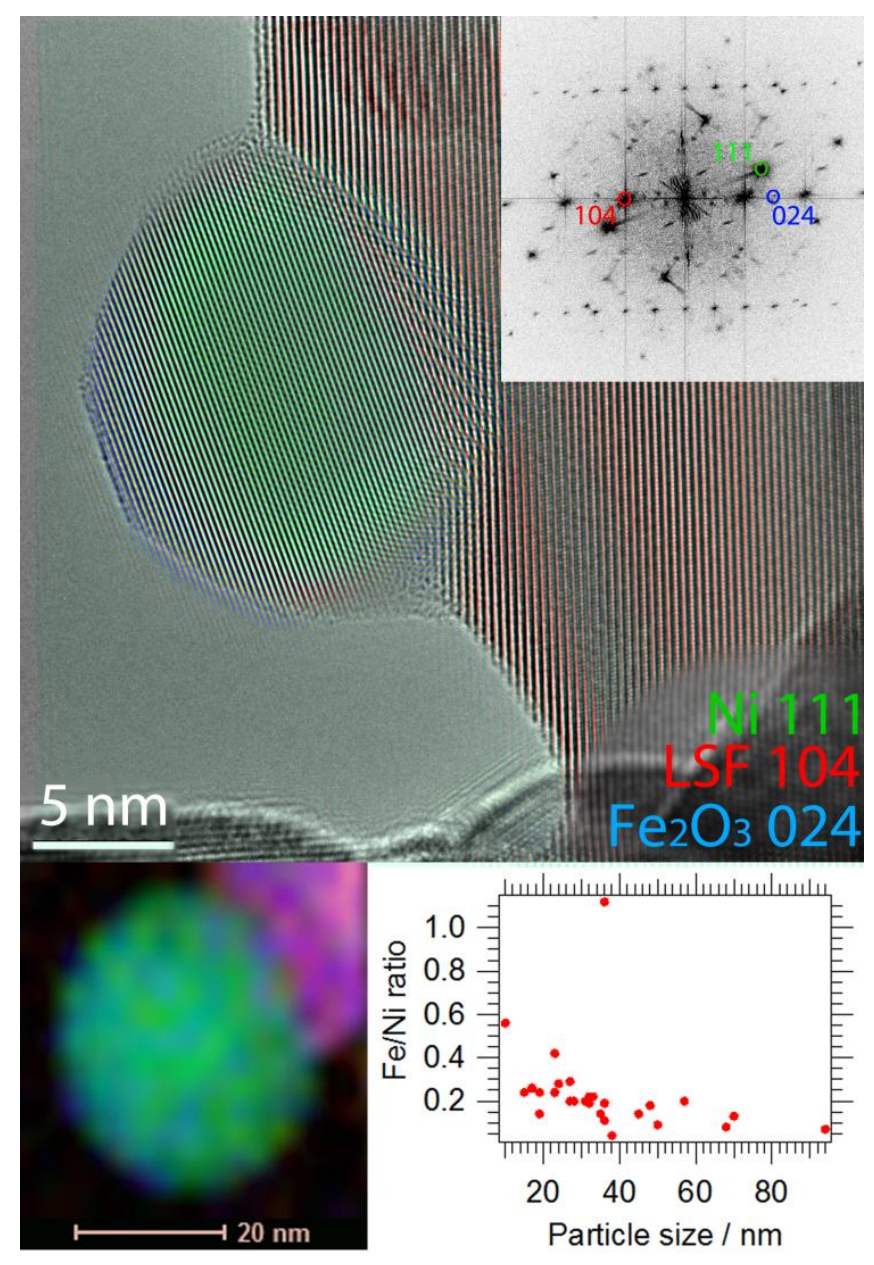

Figure 6: HRTEM image of Ni-LSF after the catalytic methane steam reforming reaction at $600{ }^{\circ} \mathrm{C}$ for $1 \mathrm{~h}$ highlighting a $\mathrm{Ni}-\mathrm{Fe}$ alloy particle (main panel). A Fast-Fourier transform (right top) used to color-code phase-specific lattice fringes of $\mathrm{Ni}$ (green), LSF (red) and $\mathrm{Fe}_{2} \mathrm{O}_{3}$ (blue), an EELS map (lower left) of a single alloyed Ni-Fe particle (superposition of Fe-L (blue), Ni-L (green) and La-L edge (red) intensities) and a plot of the Fe/Ni ratio vs. the $\mathrm{Ni}$ particle size (lower right) are shown as insets. 


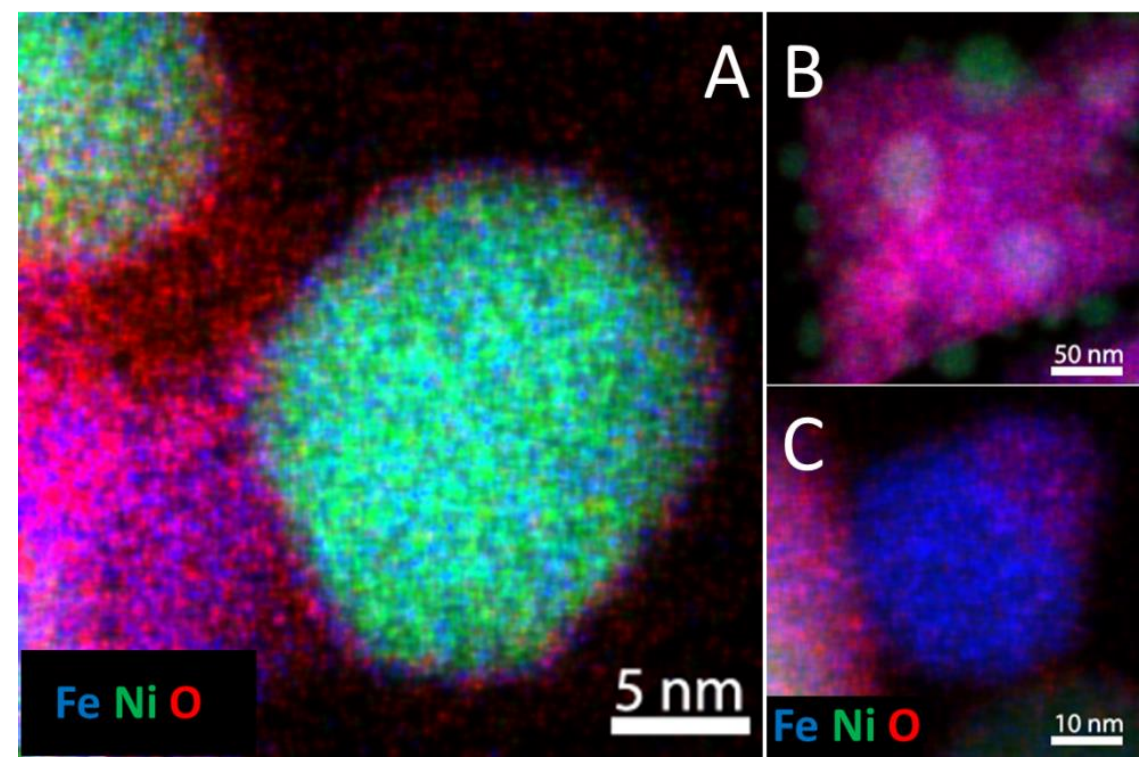

Figure 7: EDX maps of Ni-LSF after the catalytic methane steam reforming measurement at $600{ }^{\circ} \mathrm{C}$ : alloyed $\mathrm{Ni} / \mathrm{Fe}$ particle with an iron oxide shell (A), overview of $\mathrm{Ni}$ and Fe particles on LSF (B) and exsolved Fe particle with partly oxidized surface (C).

In summary, the studies up to this point indicate slight, possibly electronic, modifications of pure Ni on Ni-STF through modest Ni-Fe intermixing especially at the interface, but a more or less absence of metallic Ni on LSF under comparable experimental conditions. Differences in the influence on catalytic reactivity are already to be expected, since Ni-STF should basically exhibit the catalytic profile of metallic $\mathrm{Ni}$ (with slight variations due to minute alloying), Ni-on-LSF, in contrast, should show more pronounced changes in activity and/or selectivity.

\subsection{Reactivity Tests}

As a second step, the reactivity in methanation from $\mathrm{CO}$ and $\mathrm{CO}_{2}$ as well as the reverse reaction, methane steam reforming, has been tested. Both reactions are important due to $\mathrm{CO}_{2}$ utilization, energy conversion and sustainability issues, and because a large data set especially on different pure perovskite systems is readily available. This, hence, serves as a particular 
convenient scientific basis not only for reactivity interpretation, but also for assessing the influence of $\mathrm{Ni}$, the $\mathrm{Ni}$-perovskite interface and/or chemically modified $\mathrm{Ni}$ (e.g. by alloying).

Figure 8 shows the comparison of $\mathrm{CO}_{2}$ methanation reactivities. Already at a glance, qualitative differences are clearly visible. Starting with the $\mathrm{Ni}-\mathrm{Al}_{2} \mathrm{O}_{3}$ reference catalyst, it shows a qualitatively expected behavior [44]. At around $200{ }^{\circ} \mathrm{C}, \sim 100{ }^{\circ} \mathrm{C}$ lower compared to ref. [45] due to different preparation methods used, the normalized methanation rate increases (consumption of both hydrogen and $\mathrm{CO}_{2}$ ) and peaks at $250{ }^{\circ} \mathrm{C}$. Methane (green trace) is formed according to the reaction stoichiometry. At temperatures above $300{ }^{\circ} \mathrm{C}$, the reaction is reversed and the methane steam reforming reaction rate increases (formation of $\mathrm{H}_{2}$ and $\mathrm{CO}_{2}$ with the associated consumption of methane). On both Ni-STF and Ni-LSF related reaction profiles are observed. Ni-STF appears to be very similar to the reference catalyst, with the only difference of a higher reaction onset temperature at about $300{ }^{\circ} \mathrm{C}$. A measurable methane steam reforming reaction rate appears therefore also at higher temperatures of about $400{ }^{\circ} \mathrm{C}$. For both the $\mathrm{Ni}-\mathrm{Al}_{2} \mathrm{O}_{3}$ reference catalyst and the Ni-STF sample, this indicates a shift of the equilibrium towards $\mathrm{CO}$ at higher reaction temperatures. The difference in onset temperature can be tentatively explained by obvious kinetical hindering of both routes of the $\mathrm{CO}_{2}$ methanation equlibrium on Ni-STF, which according to the electron microscopy results might be due to electronic modification of $\mathrm{Ni}$ by partial alloying with $\mathrm{Fe}$, mostly at the metal-oxide interface. A detailed look at the reaction profile at the highest temperatures reveals, that in the methane steam reforming part, only $\mathrm{CO}$ is formed and $\mathrm{CO}_{2}$ stays on a constant level up to 570 ${ }^{\circ} \mathrm{C}$. Above, $\mathrm{CO}_{2}$ is apparently re-consumed due to the inverse water-gas shift reaction proceeding on STF [30]. On Ni-LSF, the onset of the reaction rate is shifted to even higher temperatures of about $370{ }^{\circ} \mathrm{C}$ and a methane steam reforming reaction rate is only observed at around $550{ }^{\circ} \mathrm{C}$. A rate of the competing inverse water-gas shift reaction is obtained at even lower temperatures, in accordance with previous studies on pure LSF [30]. This is also 
directly revealed by the reaction profiles of Figure 9, panels A (Ni-LSF) and panel C (NiSTF). The overall smaller reaction rates of Ni-LSF are attributed to the much more pronounced alloying (cf. Figure 4). The rate maximum of methane formation is generally smaller, because the $\mathrm{CO}_{2}$ methanation rate is largely suppressed until $300{ }^{\circ} \mathrm{C}$.

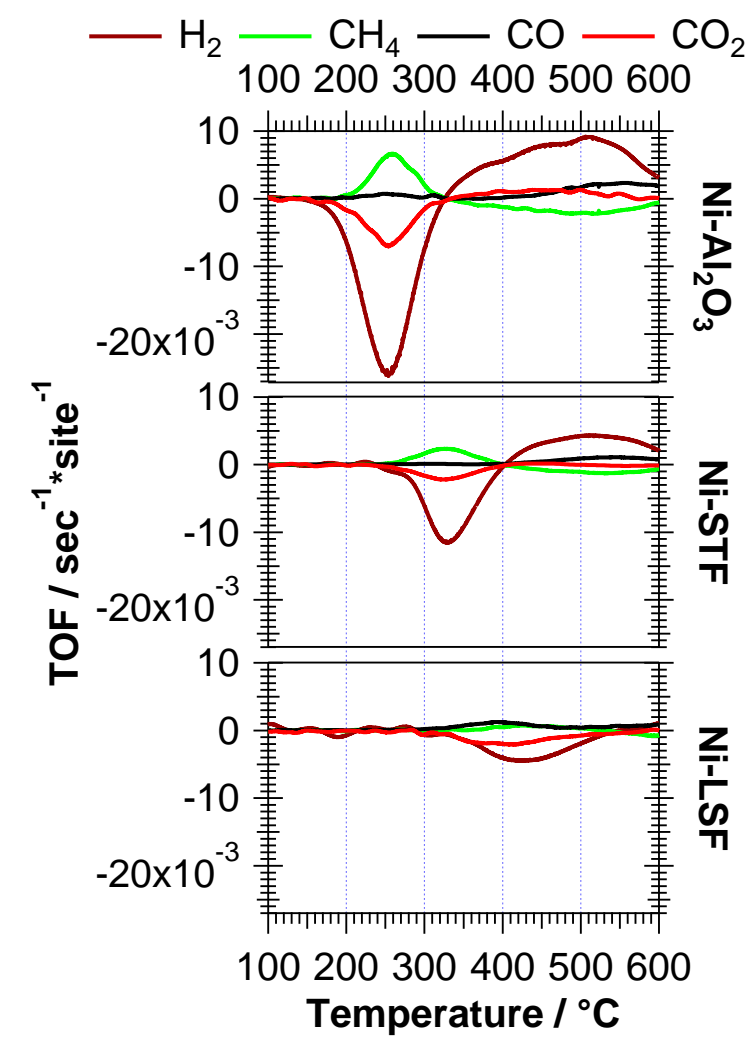

Figure 8: Normalized $\mathrm{CO}_{2}$ methanation reaction rates from $\mathrm{CO}_{2}\left(\mathrm{CO}_{2}+4 \mathrm{H}_{2} \rightarrow \mathrm{CH}_{4}+\right.$ $2 \mathrm{H}_{2} \mathrm{O}$ ) on the $\mathrm{Ni}-\mathrm{Al}_{2} \mathrm{O}_{3}$ reference catalyst (upper panel) in comparison to the same reaction on Ni-STF (middle panel) and Ni-LSF (lower panel). Reaction conditions: 20 mbar $\mathrm{CO}_{2}, 80$ mbar $\mathrm{H}_{2}$ and 25 mbar $\mathrm{H}_{2} \mathrm{O}, 10$ mbar Ar, He added to 1 bar total pressure. Heating rate: $5{ }^{\circ} \mathrm{C}$ $\min ^{-1}$

Before we focus on the detailed reaction profile of methane steam reforming and methanation starting from $\mathrm{CO}$, a brief review of the catalytic properties of pure LSF and STF should be given, as this considerably facilitates the understanding of the reaction profiles on the Nisupported perovskite systems. On both LSF and STF, pre-reduction in hydrogen significantly 
influenced the reactivity in (inverse) water-gas shift reaction, methane oxidation and $\mathrm{CO}$ oxidation due to the ability to adsorb hydrogen on the perovskite surface and even incorporate large amounts of hydrogen into the bulk. (Inverse) water-gas shift reactivity was observed between $400{ }^{\circ} \mathrm{C}$ (water-gas shift) and $500{ }^{\circ} \mathrm{C}$ (inverse water-gas shift). A methane oxidation rate (with released lattice oxygen) was measured at around $400{ }^{\circ} \mathrm{C}$ and above, as well as CO oxidation reactivity starting at $250{ }^{\circ} \mathrm{C}$ by reduction of the lattice oxygen of the perovskite [30]. Note that apart from the hydrogen interaction ability of LSF and STF, eventually also forming hydride entities, such species must in principle also be considered by hydrogen interaction with the $\mathrm{Ni}$ particles. However, formation of a considerable amount of $\mathrm{Ni}-\mathrm{H}$ species is excluded due the rather mild reduction treatments [46].

With this information in mind, the methane steam reforming reaction profiles on Ni-LSF (Figure 9 A) and Ni-STF (Figure 9 C) can be interpreted as follows: the principal reactivity in methane steam reforming indirectly already follows from the $\mathrm{CO}_{2}$ methanation reaction profiles displayed in Figure 8. A methane reaction rate was observed above $420{ }^{\circ} \mathrm{C}$ and 550 ${ }^{\circ} \mathrm{C}$ for Ni-STF and Ni-LSF, respectively (Figure 9). A closer look at Figure $9 \mathrm{C}$ reveals that this is corroborated by the deliberate methane steam reforming experiments on Ni-STF. Methane consumption starts at around $420-430{ }^{\circ} \mathrm{C}$ and in parallel, the hydrogen, $\mathrm{CO}$ and $\mathrm{CO}_{2}$ rates increase according to the stoichiometry of reaction (3) highlighted in the Experimental section. While the $\mathrm{CO}$ rate more or less steadily increases up to $600{ }^{\circ} \mathrm{C}$, the $\mathrm{CO}_{2}$ rate peaks below $450{ }^{\circ} \mathrm{C}$. In fact, above $500{ }^{\circ} \mathrm{C}$ Ni-free STF shows inverse water-gas shift reactivity, i.e. $\mathrm{CO}_{2}$ and $\mathrm{H}_{2}$ back-react to $\mathrm{CO}$ and $\mathrm{H}_{2} \mathrm{O}$ [30]. This can also be seen in the $\mathrm{H}_{2}$ and $\mathrm{CO}$ rate profiles: as soon as $\mathrm{CO}_{2}$ rate reverses, the $\mathrm{H}_{2}$ rate decrease accordingly and $\mathrm{CO}$ formation reaccelerates. A methane conversion of about $90 \%$ at $600{ }^{\circ} \mathrm{C}$ is finally obtained. Note that in contrast to what was observed in Figure 8, this onset is the factual onset of the methane steam reforming reaction on Fe-modified Ni on STF. The corresponding experiments on Ni-LSF are 
clearly different (Figure 9 A). The normalized methane steam reforming reaction rate increases only at much higher temperatures $\mathrm{T} \geq 500{ }^{\circ} \mathrm{C}$, which is again consistent with the reversal of the methanation reaction behavior of Ni-LSF in Figure 8. Hydrogen evolution is observed accordingly, but sets in at around $350{ }^{\circ} \mathrm{C}$, i.e. at $150{ }^{\circ} \mathrm{C}$ lower temperature. Obviously, hydrogen is released from the sample before the actual steam reforming reaction rate accelerates. This can only consistently interpreted by release of hydrogen previously introduced by the pre-reduction treatment at $600{ }^{\circ} \mathrm{C}$ and/or partial water quenching of oxygen defect sites [30]. The former was checked in a blank test reaction without any reactive gas. Hence, two different pathways of hydrogen release with varying contribution as a function of temperature are clearly observed. More interesting, however, is that only very small CO and $\mathrm{CO}_{2}$ rates have been observed, despite the clear indication of methane conversion. Eventually, $\mathrm{CO}$ and $\mathrm{CO}_{2}$ desorb after prolonged heating at $600{ }^{\circ} \mathrm{C}$ in a ratio of $2: 1$ (the onset of desorption is already seen at the highest reaction temperatures, whereby the isothermal part is not shown for the sake of clarity).

Figure 9, panel D, highlights the direct CO methanation reaction on Ni-STF (i.e. no deliberate admission of water). Two reactions starting parallel at around $350{ }^{\circ} \mathrm{C}$ are clearly visible: $\mathrm{CO}$ methanation to methane and a parallel increase of the $\mathrm{CO}_{2}$ signal. Araki and $\mathrm{Hu}$ et al. $[47,48]$ observed the same profile on $\mathrm{Ni} / \mathrm{Al}_{2} \mathrm{O}_{3}$. They propose the $\mathrm{CO}_{2}$ signal to arise from only the Boudouard reaction ( $2 \mathrm{CO} \rightleftarrows \mathrm{C}+\mathrm{CO}_{2}$ ), which we suppose in our case to be unlikely because during the oxidation reaction we never found any indication for carbon deposition. An alternative explanation for this catalytic pattern could be given in terms of a complex reaction network of simultaneously proceeding reactions

$$
\mathrm{CO}+3 \mathrm{H}_{2} \rightarrow \mathrm{CH}_{4}+\mathrm{H}_{2} \mathrm{O}(\mathrm{CO} \text { methanation, reaction (2)) }
$$

and 


$$
2 \mathrm{CO}+2 \mathrm{H}_{2} \rightarrow \mathrm{CH}_{4}+\mathrm{CO}_{2} \text { (reversal of methane dry reforming). }
$$

In summary, this yields the reaction

$$
3 \mathrm{CO}+5 \mathrm{H}_{2} \rightarrow 2 \mathrm{CH}_{4}+\mathrm{CO}_{2}+\mathrm{H}_{2} \mathrm{O}
$$

which satisfactorily reproduces the observed partial pressures of the reactants shortly before the maximum of methane formation, i.e. at around $430{ }^{\circ} \mathrm{C}$ (cf. also Figure S7). The methane steam reforming reaction rate accelerates notably at around $450{ }^{\circ} \mathrm{C}$ (with in-parallel $\mathrm{CO}$ formation). Simultaneously, a $\mathrm{CO}_{2}$ reaction rate is observed, at around $400{ }^{\circ} \mathrm{C}$ (as determined previously on pure STF, the inverse water-gas shift reaction forms $\mathrm{CO}$ and $\mathrm{H}_{2} \mathrm{O}$ in this temperature region [30]). The potential influence of the electronic modification on $\mathrm{Ni}$ by alloying is also directly visible in the comparison with the $\mathrm{CO}$ methanation on the purely metallic Ni reference catalyst. Increase of the normalized $\mathrm{CO}$ rate on the latter has been observed at around $150{ }^{\circ} \mathrm{C}$, that is, $200{ }^{\circ} \mathrm{C}$ lower than on Ni-STF. Furthermore, on the reference catalyst the $\mathrm{CO}_{2}$ rate has been clearly linked to the Boudouard reaction, which follows from associated oxidation treatments after the catalytic reaction, clearly showing additional $\mathrm{CO}_{2}$ arising from obviously deposited carbon (not shown here). This is a clear difference to what is observed on Ni-STF.

In direct comparison, the corresponding experiments on Ni-LSF reveal a distinctly different behavior concerning methane chemistry (Figure 9, panel B). A CO oxidation rate peaking at $230{ }^{\circ} \mathrm{C}$, essentially revealing inverse water-gas shift reactivity, can be observed. This follows from the exact synchronous decrease and increase of the $\mathrm{CO}$ and $\mathrm{CO}_{2}$ rates and, at higher temperatures, $\mathrm{CO}_{2}$ and $\mathrm{H}_{2}$. Methane reactivity is clearly absent, and this is understandable on the basis of the structural disorder and the high degree of alloying of the Ni-LSF sample after pre-reduction: exsolved iron particles are observed alongside alloyed $\mathrm{Ni}-\mathrm{Fe}$ particles, which chemically alter the Ni particles and accordingly suppress the Ni-typical methane chemistry. 
Note, that a direct comparison with Figure 8, panel C and Figure 9, panel A at first yields contradicting results, as in both cases methane rates are clearly observed. However, the reduction conditions as used for Figure 9, panel B are extremely harsh due the simultaneous presence of both $\mathrm{H}_{2}$ and $\mathrm{CO}$. Therefore, the structural rupture of the LSF lattice and the subsequent chemical alteration of the Ni particles are much more pronounced. The only feature with being still necessary to discuss is the rather sharp drop in hydrogen starting at around $270{ }^{\circ} \mathrm{C}$. At the moment, we ascribe this to the further reduction of the sample in $\mathrm{CO}$ up to $270{ }^{\circ} \mathrm{C}$, obviously creating reactive centers being not accessible by "simple" hydrogen reduction in the pre-treatment, but providing adsorption sites for hydrogen.

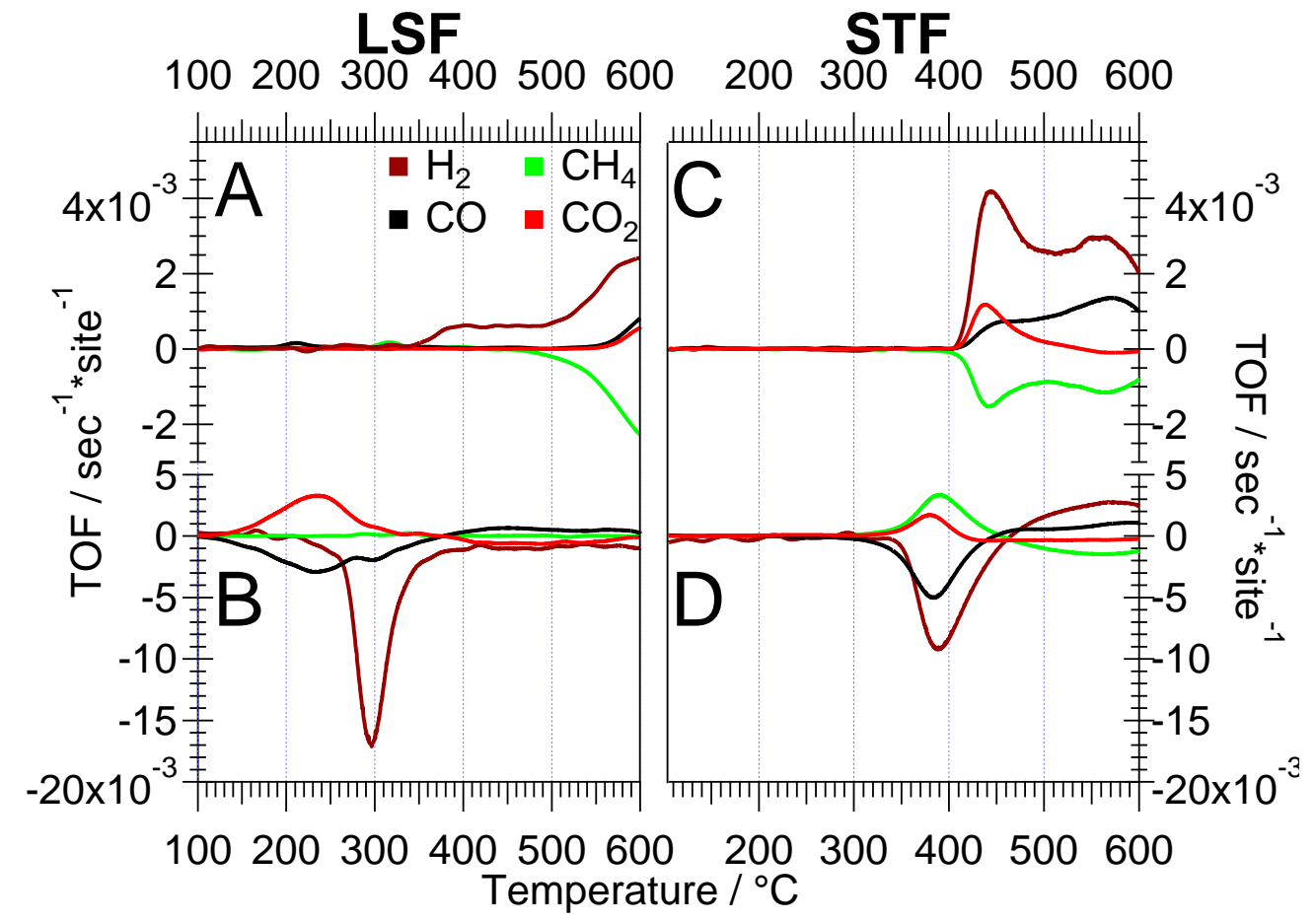

Figure 9: Normalized methane steam reforming $\mathrm{CH}_{4}+x \mathrm{H}_{2} \mathrm{O} \rightarrow \mathrm{CO}_{x}+(2+x) \mathrm{H}_{2}$ (panel A and $\mathrm{C} ; 25$ mbar $\mathrm{H}_{2} \mathrm{O}$ and 25 mbar $\left.\mathrm{CH}_{4}\right)$, as well as $\mathrm{CO}$ methanation $\left(\mathrm{CO}+3 \mathrm{H}_{2} \rightarrow \mathrm{CH}_{4}+\right.$ $\mathrm{H}_{2} \mathrm{O}$; panels B and D; 20 mbar CO, $60 \mathrm{mbar}^{\mathrm{H}} \mathrm{H}_{2}$ ) reaction rates on Ni-LSF (panels A-B) and Ni-STF (panels C-D). 10 mbar Ar added for correction of gas withdrawal, He added to 1 bar total pressure. Heating rate: $5{ }^{\circ} \mathrm{C} \min ^{-1}$. 
The participation of elemental $\mathrm{Ni}$ in $\mathrm{Ni}$-containing perovskite systems following reductive activation or treatment in methanation or steam reforming mixtures is already a documented phenomenon, but as such, in the overwhelming majority of experiments "accidental" and therefore notoriously different to control. A particular instructive example is provided by studies on $\mathrm{LaNi}_{\mathrm{x}} \mathrm{Fe}_{1-\mathrm{x}} \mathrm{O}_{3}$ perovskites in methane reforming [8-10]: in this case, the structural changes have been directly linked to the Ni content. This also affected the regeneration of the catalyst. Low Ni loadings led to small $\mathrm{Ni}$ particles supported on the structurally intact perovskite (with possible regeneration), higher loadings to $\mathrm{Ni}$ particles on the ruptured perovskite, i.e. on $\mathrm{LaFeO}_{3}$ and $\mathrm{La}_{2} \mathrm{O}_{3}$ (no regeneration possible). The fate of the catalyst after contact to reaction mixtures has been observed to be also strongly dependent on their reducing power: oxyreforming of methane led to $\mathrm{Ni}$ particles, methane dry reforming to $\mathrm{Ni}-\mathrm{Fe}$ alloy particles. Similar dispersed Ni particles alongside La-oxycarbonate species have also been observed following $\mathrm{CO}_{2}$ methanation over $\mathrm{LaNiO}_{3}$ catalysts [12]. Furthermore, after performing simultaneous steam and $\mathrm{CO}_{2}$ reforming of methane and oxidative conversion of methane to syngas over $\mathrm{LaNiO}_{3}$ catalysts, Ni-on- $\mathrm{La}_{2} \mathrm{O}_{3}$ structures are observed, leading to improved methane conversion [14]. Exsolution of $\mathrm{Ni}$ from $\mathrm{La}_{1-\mathrm{x}} \mathrm{Sr}_{\mathrm{x}} \mathrm{NiO}_{3}$ perovskites during dry reforming of methane leading to Ni particles, $\mathrm{SrCO}_{3}$ and La-oxycarbonate species with enhanced dry reforming activity [16]. On the contrary, Wang et al. provided data on Ni$\mathrm{LaFeO}_{3}$ systems with deliberate impregnation of $\mathrm{LaFeO}_{3}$ with Ni using two different citrate complexing methods. Depending on the pathway of preparation, $\mathrm{Ni}-\mathrm{LaFeO}_{3}$ or $\mathrm{Ni}-\mathrm{Fe} / \mathrm{Ni}$ $\mathrm{LaFeO}_{3}-\mathrm{La}_{2} \mathrm{O}_{2} \mathrm{CO}_{3}$ systems result, with different activities and resistance against coking [13]. In turn, these systems come closest to the Ni-perovskite materials discussed in this work and in fact, show some similarities. By comparison of Ni-STF and Ni-LSF, the different reducibility and iron content of LSF and STF manifested itself especially in a different extent of Fe-Ni alloy formation, which can be directly linked to changes in catalytic activity: Ni$\mathrm{STF}$, due to the smaller extent of alloy formation (at the interface), exhibits an activity pattern 
in $\mathrm{CO}_{2}$ methanation comparable to a $\mathrm{Ni}-\mathrm{Al}_{2} \mathrm{O}_{3}$ catalyst, where alloy formation is absent. In contrast, Ni-LSF is clearly different from both other catalysts. This difference is also directly visible in the $\mathrm{CH}_{4}$ TOF values and the apparent activation energies, derived both from the TEM and the CO adsorption measurements (Table 1). Ni-STF has a slightly higher apparent activation energy $\left(118 \mathrm{~kJ}\right.$ mole $\left.{ }^{-1}\right)$ than $\mathrm{Ni}-\mathrm{Al}_{2} \mathrm{O}_{3}\left(103 \mathrm{~kJ}\right.$ mole $\left.{ }^{-1}\right)$ and a comparable maximum TOF: $2.4 \times 10^{-3} \mathrm{~s}^{-1}$ (at $600 \mathrm{~K}$ ) versus $6.6 \times 10^{-3} \mathrm{~s}^{-1}$ (at $530 \mathrm{~K}$ ). Ni-LSF in contrast has a much higher apparent activation energy of $146 \mathrm{~kJ} \mathrm{~mole}^{-1}$ and also the TOF maximum is the lowest of the three catalysts $\left(7.6 \times 10^{-4} \mathrm{~s}^{-1}\right.$ (at $\left.\left.700 \mathrm{~K}\right)\right)$. The $\mathrm{CH}_{4}$ TOF values for $\mathrm{CO}_{2}$ methanation on the $\mathrm{Ni}-\mathrm{Al}_{2} \mathrm{O}_{3}$ reference catalyst are in good agreement with literature data [49], and at least for the Ni-STF sample in methanation and methane reforming reactions are in the range of those obtained on comparable $\mathrm{Ni}$ and related catalyst systems [50-60] (e.g. $\mathrm{CO}_{2}$ methanation on Ni$\mathrm{Al}_{2} \mathrm{O}_{3}: \mathrm{CH}_{4}$-TOF $0.69 \mathrm{~s}^{-1}(573 \mathrm{~K})$ [49]; Ni-ZrO $2: \mathrm{CH}_{4}$-TOF $0.4 \mathrm{~s}^{-1}$ (573 K) [50]; Rh-TiO 5.9 $\times 10^{-3} \mathrm{~s}^{-1}$ [50]; NiRu-SiO ${ }_{2}: 8.3 \times 10^{-2} \mathrm{~s}^{-1}$ [51]; $\mathrm{CH}_{4}$ reforming: $\mathrm{Ni}-\mathrm{SiO}_{2}: \mathrm{CH}_{4}-\mathrm{TOF} 0.65 \mathrm{~s}^{-1}$ (773 K) [60]). Direct correlation to literature-reported values is sometimes difficult due to different catalytic setups used (i.e. most data are obtained using flow reactor setups) and as a consequence, changes in the equilibrium situation in the batch reactor. Note that for both $\mathrm{Ni}$ perovskite systems no coking has been observed (as in [15]), which is a particular advantage over "simpler" perovskite catalysts, such as $\mathrm{LaNiO}_{3}$.

Table 1: Overview of apparent activation energy (Ea), maximum $\mathrm{CH}_{4}-\mathrm{TOF}$ and number of reactive sites for the $\mathrm{CO}_{2}$ methanation reaction.

\begin{tabular}{|l|r|r|r|}
\hline & Ni STF & Ni LSF & Euro Ni \\
\hline Sites TEM analysis & $2.00 \times 10^{18}$ & $1.20 \times 10^{18}$ & $9.80 \times 10^{18}$ \\
Ea / kJ & 118 & 145 & 103 \\
TOF $(\max ) / \mathrm{sec}^{-1}$ & $2.4 \times 10^{-3}(600 \mathrm{~K})$ & $7.6 \times 10^{-4}(700 \mathrm{~K})$ & $6.6 \times 10^{-3}(530 \mathrm{~K})$ \\
\hline Sites CO adsorption & $1.56 \times 10^{18}$ & $3.07 \times 10^{18}$ & $2.27 \times 10^{18}$ \\
$\mathrm{Ea} / \mathrm{kJ}$ & 117 & 147 & 106 \\
TOF $(\max ) / \mathrm{sec}^{-1}$ & $3.05 \times 10^{-3}(600 \mathrm{~K})$ & $3.06 \times 10^{-3}(700 \mathrm{~K})$ & $2.85 \times 10^{-3}(530 \mathrm{~K})$ \\
\hline
\end{tabular}


Re-addressing the particle-size dependence of alloy formation, at this point the potential catalytic consequences should be briefly addressed. This is important insofar as to detect a potential structure sensitivity and particle-size effect of the studied reactions and will also answer the possibility of a potential geometric effect on catalytic activity and selectivity. In fact, to explain the catalytic alterations during alloy formation, we propose an ensemble effect, i.e. electronic modification of Ni induced by Fe diffusion. A pure geometrical dilution effect is excluded since the amount of Fe dissolved within the Ni particles is very low.

Although a particle size effect has not been studied directly by e.g. varying the particle size, the fact that alloy formation itself is not a strong function of the particle size (and considered to be the dominant catalytic steering factor), a strong structure sensitivity is hence excluded. The role of the metal-support, and specifically the metal-perovskite interface plays in affecting the catalytic reactivity, has been addressed in a number of recent works. In the water-gas shift reaction, a direct effect of the particle size perimeter has been elucidated [61] and particular focus has been put on establishing structure-activity relationships in abatement of $\mathrm{NO}$ and $\mathrm{N}_{2} \mathrm{O}$ using $\mathrm{LaFeO}_{3}$-supported $\mathrm{Pt}$ particles [31] and $\mathrm{PdO}_{x}$ [32] particles exsolved from $\mathrm{LaCo}_{0.95} \mathrm{Pd}_{0.05} \mathrm{O}_{3}$ perovskites. Clear trends in the correlation between reaction rates and length of interfacial region have been established and critical particle size diameters determined, where the structure-sensitivity of the reaction changes. We did not observe such a structure sensitivity, at least not with respect to the degree of alloying.

\section{Conclusions}

Exemplarily shown for small $\mathrm{Ni}$ particles on the perovskites $\mathrm{La}_{0.6} \mathrm{Sr}_{0.4} \mathrm{FeO}_{3-\delta}$ and $\mathrm{SrTi}_{0.7} \mathrm{Fe}_{0.3} \mathrm{O}_{3-\delta}$, structural and morphological manifestations of metal-support interaction in complex metal-oxide systems and its catalytic consequences are highlighted. Strong or even 
reactive metal-support interaction on "simple" metal-oxide systems is already a complex topic, but in particular the structural consequences are much more pronounced in structurally complexer oxides. Some features, such as the exsolution and the subsequent formation of alloy nanoparticles, bear some resemblance to reactive metal-support interaction effects in other metal-oxide systems, also leading to alloy or intermetallic compound formation [62]. However, isolated exsolved metal particles are obviously exclusively observed for complexer systems. Studies on the metal-support interaction in complex oxide systems still are in their infant's shoes and a long way has to be gone until full understanding is obtained. Nevertheless, the use of complexer oxidic support materials might offer exciting new possiblities in tailoring the catalytic performance. Exemplified by the use of two representative perovskite materials STF and LSF, we have shown how the reducibility of the support through the associated degree of alloying steers the catalytic activity and selectivity. STF as less reducible material exhibits only a minor degree of $\mathrm{Ni}$-Fe alloying - hence the introduced electronic modifications of the $\mathrm{Ni}$ particles give rise to slightly altered catalytic behavior in methanation and steam reforming reactions in comparison to clean supported $\mathrm{Ni}$. LSF, in contrast, is much more reducible, giving rise to a higher degree of $\mathrm{Ni}-\mathrm{Fe}$ alloying and an associated suppressed catalytic performance. Therefore, by careful selection of the complex oxidic support and the reduction conditions, a controlled route to supported $\mathrm{Ni}-\mathrm{Fe}$ catalysts is eventually opened. In principle, the ideas outlined in the present contribution can be deliberately extended to similar systems and it is hoped, that subsequent studies on other complex supporting oxide systems are triggered, e.g. using spinel phases or other perovskite materials. This is deemed especially important, since these oxides gain increasing interest in the catalytic community in a wide range of application areas. 


\section{Acknowledgments}

We thank the FWF (Austrian Science Foundation) for financial support under the project F4503-N16. The work was performed at the University of Innsbruck within the platform "Material- and Nanoscience". Perovskite samples were kindly provided by A. K. Opitz, Institute of Materials Chemistry, Technical University Vienna. The research leading to these results has received funding from the European Union Seventh Framework Programme under Grant Agreement 312483 - ESTEEM2 (Integrated Infrastructure Initiative-I3. M.H and M.G. thank the Deutsche Forschungsgemeinschaft (DFG) for support within the grant HE 7192/1-1 


\section{References}

[1] M. A. Pena, J. L. G. Fierro, Chem. Rev. 101 (2001) 1981-2017

[2] S. Royer, D. Duprez, F. Can, X. Courtois, C. Bstiot-Dupeyrat, S. Lassiri, H. Alamdari, Chem. Rev. 114 (2014) 10292-10368

[3] J. L.G. Fierro, Catal. Rev. Sci. Eng. 34 (1992) 321-336

[4] T. Seiyama, Catal. Rev. Sci. Eng. 34 (1992) 281-300

[5] K. Ichimura, Y. Inoue, I. Yasumori, Catal. Rev. Sci. Eng. 34 (1992) 301-320

[6] J. Villoria, N. Mota, S. A. Al-Sayari, M. Alvarez-Galvan, Micro- and Nanosystems 4 (2012) 231-252

[7] M. A. Ulla, R. A. Migone, J. O. Petunchi, E. A. Lombardo, J. Catal. 105 (1987) 107-119

[8] S. Choi, S. Moon, Catal. Today 146 (2009) 148-153

[9] H. Provendier, C. Petit, A. Kiennemann, C. R. Acad. Sci. Paris, Serie Iic 4 (2001) 57-66

[10] H. Provendier, C. Petit, C. Estournes, S. Libs, A. Kiennemann, Appl. Catal. A 180 (1999) 163-171

[11] H. Provendier, C. Petit, C. Estournes, A. Kiennemann, C. R. Surf. Sci. Catal. 119 (1998) $741-749$

[12] J. Gao, L. Jia, W. Fang, Q. Li, H. Song, J. Fuel Chem. Technol. 37 (2009) 573-577

[13] H. Wang, Y. Fang, Y. Liu, X. Bai, J. Nat. Gas Chem. 21 (2012) 745-752

[14] V. R. Choudhary, B. S. Uphade, A. A. Behelkar, J. Catal. 163 (1996) 312-318

[15] K. Urasaki, Y. Sekine, S. Kawabe, E. Kikuchi, M. Matsukata, Appl. Catal. A 286 (2005) 
[16] G. Valderrama, M. R. Goldwasser, C. Urbina de Navarro, J. M. Tatibouet, J. Barrault, C. Batiot-Dupeyrat, F. Martinez, Catal. Today 107-108 (2005) 785-791

[17] P. Sabatier, J. B. Senderens, J. Soc. Cheim. Ind. 21 (1902) 504-506

[18] W. Wei, G. Jinlong, Frontiers of Chemical Science and Engineering 5 (2011) 2-10

[19] G. Alex Mills, F. W. Steffgen, Catal. Rev. Sci. Eng. 8 (1974) 159-210

[20] T. Schaaf, J. Grünig, M. Schuster, T. Rothenfluh, A. Orth, Ebergy, Systainability and Society 4 (2014) 1-14

[21] D. J. Elliott, J. H. Lunsford, J. Catal. 57 (1979) 11-26

[22] A. K, Opitz, A. Nenning, C. Rameshan, R. Rameshan, R.Blume, M. Hävecker, A. KnopGericke, G. Rupprechter, J. Fleig, B. Klötzer, Angew. Chemie Intl. Ed. 127 (2015) 2666-2670

[23] Y. Xu, A. C. Lausche, S. Wang, T. S. Khan, F. Abild-Pedersen, F. Studt, J. K. Norskov, T. Bligaard, New J. Phys. 15 (2013) 125021-1 - 125021-13

[24] L. Wang, D. L. Li, M. Koike, S. Koso, N. Nakagawa, Y. Xu, K. Tomishige, Appl. Catal. A 392 (2011) 248-255

[25] D. Neagu, G. Tsekouras, D. N. Miller, H. Menard, J. T.S. Irvine, Nature Chem. 5 (2013) 916-923 and references therein.

[26] J. M. Haag, S. A. Barnett, J. W. Richardson, K. R. Poeppelmeier, Chem. Mater. 22 (2010) 3282-3289

[27] Q. Qin, G. Wu, S. Chen, W. Doherty, K. Xie, Y. Wu, Y. Electrochem. Acta 127 (2014) 215-227.

[28] T. S. Oh, R. J. Gorte, J. M. Vohs, NAM-24, Extended Abstract O-Tu-403-12, 2015. 
[29] Y. Sun, J. Li, Y. Zeng, B. S. Amirkhiz, M. Wang, Y. Behnamian, J. J. Luo, Mater. Chem. A 3 (2015) 11048-11056

[30] R. Thalinger, A. K. Opitz, S. Kogler, M. Heggen, D. Stroppa, D. Schmidmair, R. Tappert, J. Fleig, B. Klötzer, S. Penner, J. Phys. Chem. C (2015) 2-14

[31] J. P. Dacquin, M. Cabie, C. R. Henry, C. Lancelot, C. Dujardin, S. R. Raouff, P. Granger, J. Catal. 270 (2010) 299-309

[32] Y. Wu, C. Dujardin, C. Lancelot, J. P. Dacquin, V. I. Parvulescu, M. Cabie, C. R. Henry, T. Neisius, P. Granger, J. Catal. 328 (2015) 236-247

[33] A. Opitz, Private Communication (2015)

[34] M. P. Pechini, U.S. Pat. 3,330,679 (1967)

[35] E. C. Kruissink, (1981). Coprecipitated nickel-alumina methanation catalysts, Doctoral dissertation, Delft University of Technology.

[36] E. Mashkina, A. Magerl, J. Ollivier, M. Gobbles, F. Seifert, Phys. Rev. B: Condens. Matter. Mater. Phys. 74 (2006) 214106

[37] S.K. Malik, A.G. Joshi, H.U. Anderson, X.D. Zhou, Y.X. Xie, M. Kornecki, Z. Chu, W.J. James, W.B. Yelon, J.-B. Yang, Phys. Rev. B: Condens. Matter. Mater. Phys. 66 (2002) 18441

[38] G. A. Slack, J. Appl. Phys. 31 (1960) 1571-1582

[39] M. Yousuf, P. C. Sahu, H. K. Jajoo, S. Rajagopalan, K. Govinda Rajan, J. Phys. F: Met. Phys. 16 (1986) 373

[40] J. G.Railsback, A. C. Johnston-Peck, J. Wang, J. B. Tracy, ACS Nano 4 (2010) 19131920 
[41] P. Schoubye, J. Catal. 14 (1969) 238-246

[42] R. J. Farrauto, J. Catal. 41 (1976) 482-485

[43] G. van Veen, E. C. Kruissink, E. B. M. Doesburg, J. R. H. Ross, L.L. van Reijen, React. Kin. Catal. Lett. 9 (1978) 143-148

[44] R. B. Shalvoy, B. H. Davies, R. J. Reucroft, Surf. Interf. Anal. 2 (1980) 11-16

[45] P. Riani, G. Garbarino, M. Lucchini, F. Canepa, G. Busca, J. Mol. Catal. A 383-384 (2014) $10-16$

[46] F. A. Lewis, Pure and Appl. Chem. 62 (1990) 2091-2096

[47] D. Hu, J. Gao, Y. Ping, L. Jia, P. Gunawan, Z. Zhong, G. Xu, F. Gu, F. Su, Ind. Eng. Chem. Res. 51 (2012) 4875-4886

[48] M. Araki, V. Ponec, J. Catal. 44 (1976) 439-448

[49] M. Aziz, A. Jalil, S. Triwahyono, R. Mukti, Y. Taufiq-Yap, M. Sazegar, Appl. Catal. B 147 (2014) 359-368

[50] J. C. Matsubu, V. N. Yang, P. Cristopher, J. Amer. Chem. Soc. 137 (2015) 3076-3084

[51] N. Yao, H. Ma, Y. Shao, C. Yuan, D. Lu, X. Li, J. Mater. Chem. 21 (2011) 17403-17412

[52] N. Perkas, G. Amirian, Z. Zhong, J. Teo, Y. Gofer, A. Gedanken, Catal. Lett. 130 (2009) $455-462$

[53] P. Panagiotopoulou, D. I. Kondradides, X. E. Verykos, Appl. Catal. B 88 (2009) 470-478

[54] K. O. Xavier, R. Sreekla, K. K. Rashid, K. K. M. Yusuff, Catal. Today 49 (1999) 17-21

[55] M. A. Vannice, C. C. Twu, J. Catal. 82 (1983) 213-222 
[56] S. Y. Wang, S. H. Moon, M. A. Vannice, J. Catal. 71 (1981) 167-174

[57] O. Yamazaki, K. Tomishige, K. Fujimoto, Appl. Catal. A 136 (1996) 49-56

[58] A.Parmaliana, F. Arena, F. Frusteri, S.Coluccia, L.Marchese, G.Martra, A. L. Chuvilin, J. Catal. 141 (1993) 34-47

[59] R. Graciun, B. Shereck, R. J. Gorte, Catal. Lett. 51 (1998) 149-153

[60]. J. R. Rostrup-Nielsen, J. Catal. 31 (1973) 173-199

[61] C. M. Kalamaras, S. Americanou, A. M. Efstathiou, J. Catal. 279 (2011) 287-300

[62] S. Penner, M. Armbrüster, ChemCatChem 7 (2015) 374-392 


\section{Supporting Information}

\section{Ni-perovskite interaction and its structural and catalytic consequences in methane steam reforming and methanation reactions}

Ramona Thalinger ${ }^{1}$, Martin Gocyla ${ }^{2}$, Marc Heggen ${ }^{2}$, Rafal Dunin-Borkowski ${ }^{2}$, Matthias Grünbacher $^{1}$, M. Stöger-Pollach ${ }^{3}$, Daniela Schmidmair ${ }^{4}$, Bernhard Klötzer ${ }^{1}$, Simon Penner ${ }^{1 *}$

${ }^{1}$ Institute of Physical Chemistry, University of Innsbruck, Innrain 80-82, A-6020 Innsbruck, Austria

${ }^{2}$ Ernst Ruska-Centrum und Peter Grünberg Institut, Forschungszentrum Jülich GmbH, 52425 Jülich, Germany

${ }^{3}$ University Service Centre for Transmission Electron Microscopy (USTEM), Vienna, University of Technology, Wiedner Hauptstrasse 8-10/052, A-1040, Vienna, Austria ${ }^{4}$ Institute of Mineralogy and Petrography, University of Innsbruck, Innrain 52d, A-6020 Innsbruck, Austria 


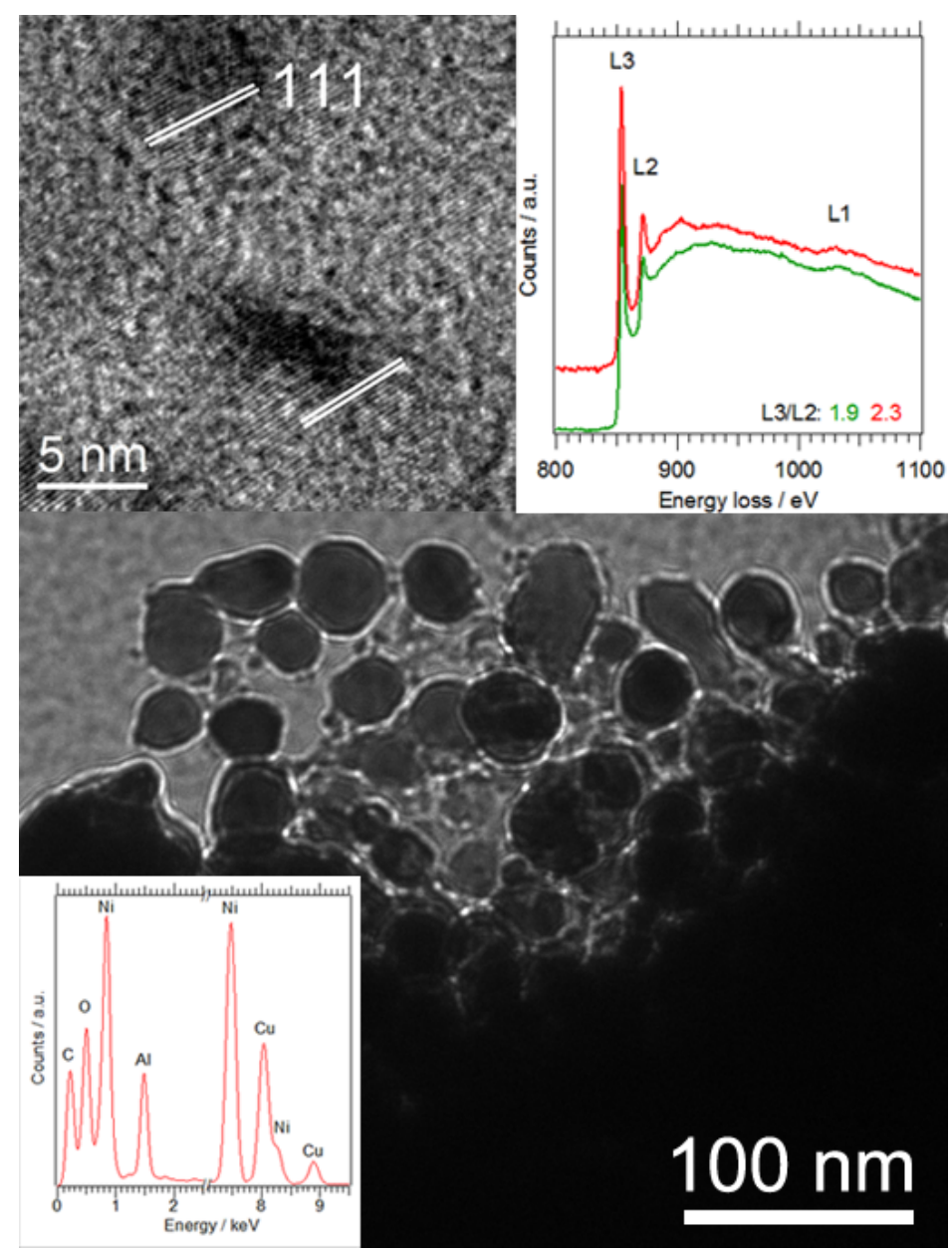

Figure S1: Overview TEM image of the $\mathrm{Ni}-\mathrm{Al}_{2} \mathrm{O}_{3}$ reference catalyst in the as-prepared state (main panel), high-resolution image of two Ni particles with (111) lattice fringes (top left). Top right: EEL spectra of different spots on the $\mathrm{Ni}^{-} \mathrm{Al}_{2} \mathrm{O}_{3}$ catalyst. Bottom left: EDX spectrum of the $\mathrm{Ni}-\mathrm{Al}_{2} \mathrm{O}_{3}$ material.

For the sake of clarity, the reference catalyst is - as in the main paper - in the following referred to as " $\mathrm{Ni}-\mathrm{Al}_{2} \mathrm{O}_{3}$ ", although the precursor material is $\mathrm{Ni}-\mathrm{AlOOH}$ (boehmite). The main panel shows an overview TEM image of a single support grain with an array of large $\mathrm{NiO}$ particles of 20 to $70 \mathrm{~nm}$. The EDX spectrum in the lower left corner reveals that indeed the catalyst is only composed of $\mathrm{Ni}, \mathrm{O}$ and $\mathrm{Al}$ - apart from carbon and $\mathrm{Cu}$ arising from the $\mathrm{Cu}$ grid covered with a perforated carbon film. In addition, both the high-resolution image (with corresponding (111) lattice planes of cubic $\mathrm{NiO}$; upper left inset) and the EEL spectra (upper right inset) reveal the predominant presence of NiO. Specifically, EEL spectra taken from 
various $\mathrm{Ni}$ particles indicate a slightly different $\mathrm{Ni} \mathrm{L}_{3} / \mathrm{L}_{2}$ ratio, indicative of $\mathrm{Ni}$ in different oxidation states. The higher the ratio, the more oxidized the Ni particles are. As the intensity ratios slightly vary (from $\mathrm{Ni} \mathrm{L}_{3} / \mathrm{L}_{2} 1.9$ to 2.3 ) we might infer the simultaneous presence of $\mathrm{Ni}$ and $\mathrm{NiO}$ particles.

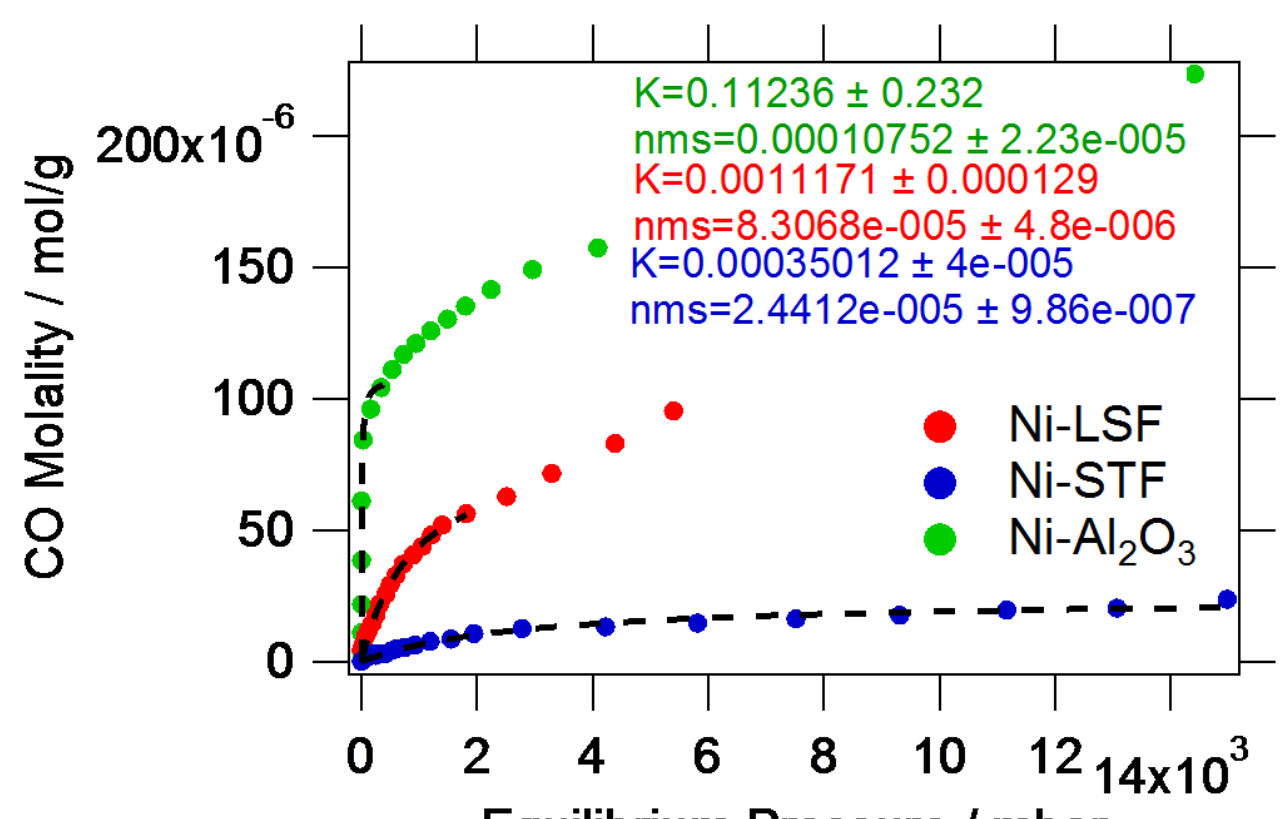

Equilibrium Pressure / mbar

Figure S2: CO adsorption measurements on Ni-LSF (red), Ni-STF (blue) and Ni- $\mathrm{Al}_{2} \mathrm{O}_{3}$ (green) at room temperature. The adsorbed amount of $\mathrm{CO}$ normalized to the catalyst mass is shown versus the $\mathrm{CO}$ equilibrium pressure. A spillover effect can be clearly seen on all three samples.

To indirectly validate the TEM measurements, the calculated accessible Ni sites, and hence the apparent activation energies and the resulting TOF values have been also determined by additional hydrogen and $\mathrm{CO}$ chemisorption measurements. Before these measurements, the catalysts were oxidized $\left(400{ }^{\circ} \mathrm{C}, \mathrm{O}_{2}, 1\right.$ bar $)$ and pre-reduced $\left(600^{\circ} \mathrm{C}, \mathrm{H}_{2}, 1 \mathrm{~h}\right)$. Hydrogen was subsequently removed by temperature-programmed desorption up to $600{ }^{\circ} \mathrm{C}$. While the hydrogen chemisorption measurements are too affected by $\mathrm{H}_{2}$ adsorption as a side reaction blurring the adsorption on the metal surface, the corresponding $\mathrm{CO}$ adsorption experiments (although the same limitation of perovskite reduction by $\mathrm{CO}$ in principle applies) indeed 
directly validate the TEM calculations. Table 1 summarizes these data. Experimentally, CO has been stepwise added at room temperature under static conditions until quasi-saturation has been observed. The corresponding data are shown in the SI. Note, as stated above, spill-over effects impede the clear saturation. To circumvent these problems, Langmuir fits have been applied and used for calculation the amount of adsorbed CO, the number of active sites and the TOF values. The accuracy of the analysis is revealed by the good agreement between TEM and adsorption studies. The apparent activation energies for the $\mathrm{CO}_{2}$ methanation reaction are calculated on the basis of an Arrhenius fit to the TOF vs. reaction temperature graphs, both derived from the TEM results and the $\mathrm{CO}$ chemisorption measurements and for all three catalysts. The fits are highlighted in the SI, the derived data jointly shown in Table 1, main paper.

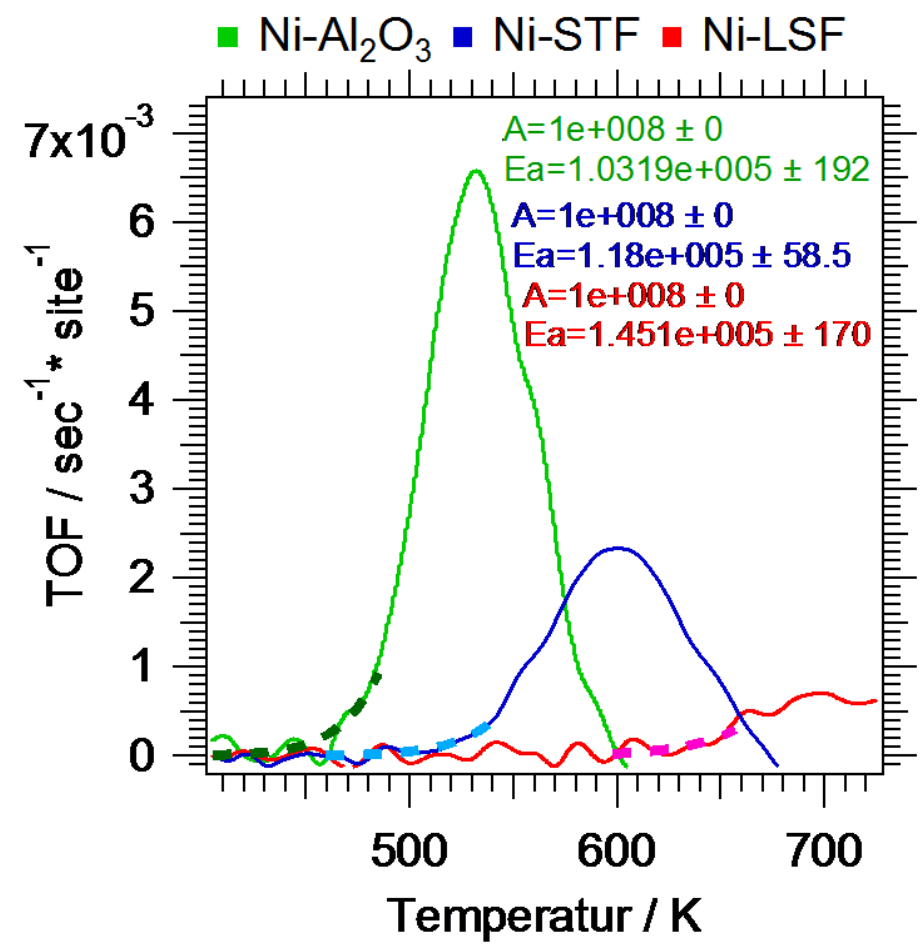

Figure S3: TOF values for the $\mathrm{CO}_{2}$ methanation reaction calculated with number of Ni sites

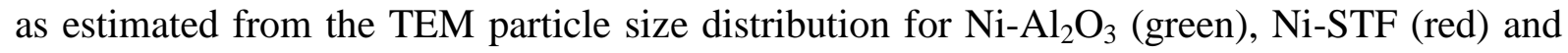
Ni-LSF (blue) with according Arrhenius fits to the initial reaction rate (dashed lines). 


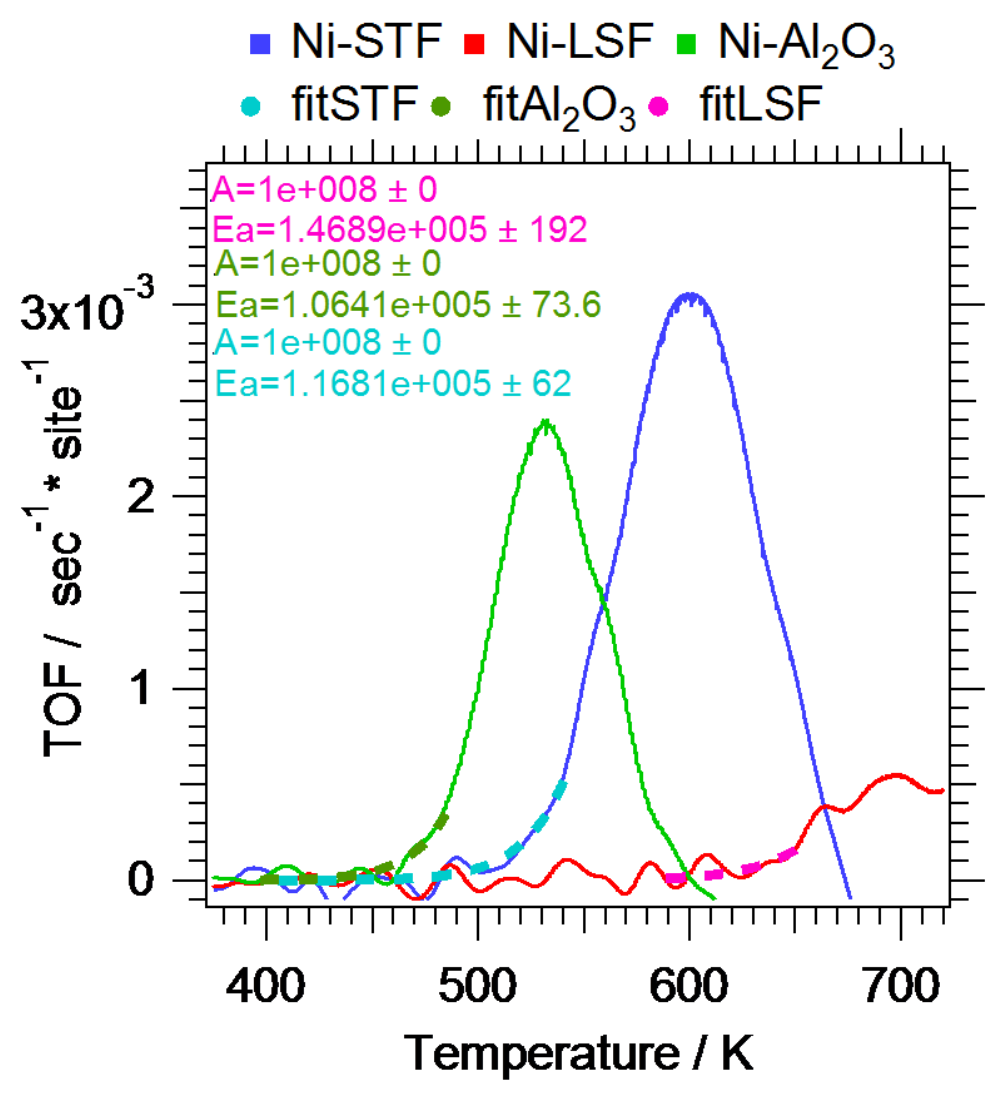

Figure S4: TOF values for the $\mathrm{CO}_{2}$ methanation reaction calculated with number of Ni sites

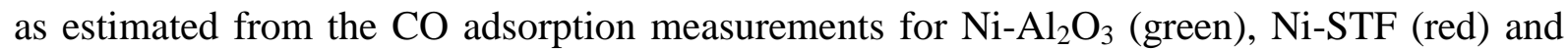
Ni-LSF (blue) with according Arrhenius fits to the initial reaction rate (dashed lines).
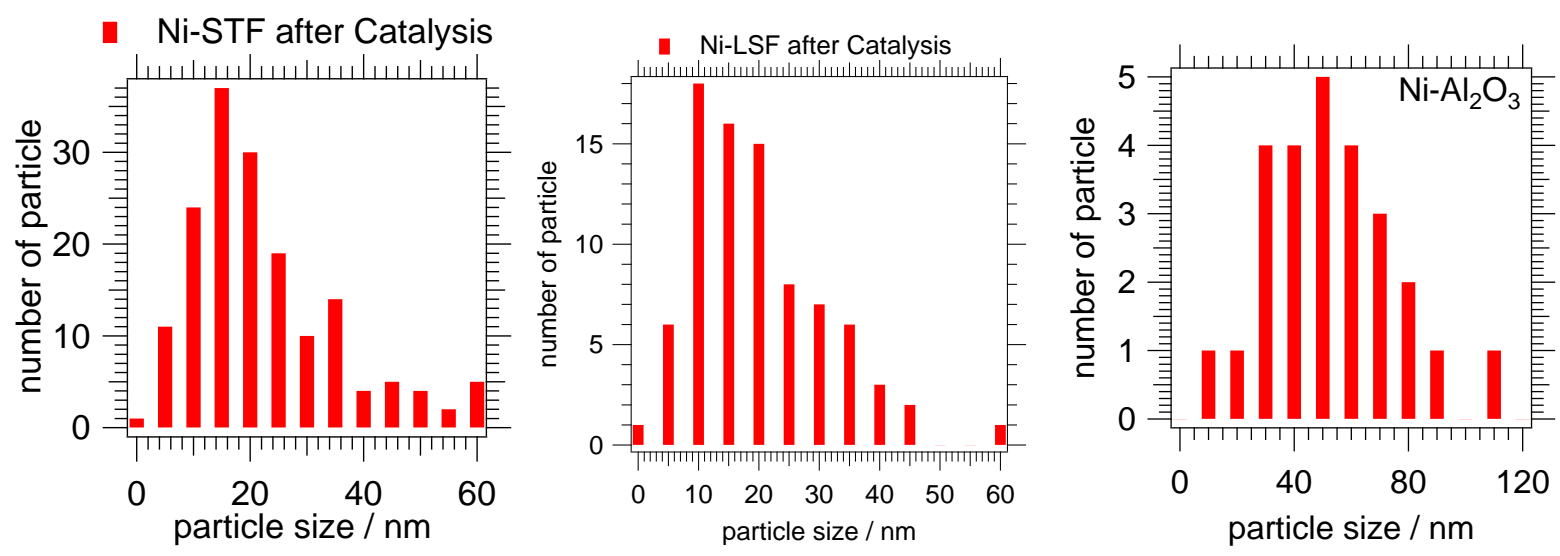

Figure S5: Particle size distribution of Ni-STF (left), Ni-LSF (middle) and $\mathrm{Ni}-\mathrm{Al}_{2} \mathrm{O}_{3}$ (right) after the $\mathrm{CO}_{2}$ methanation reaction. 


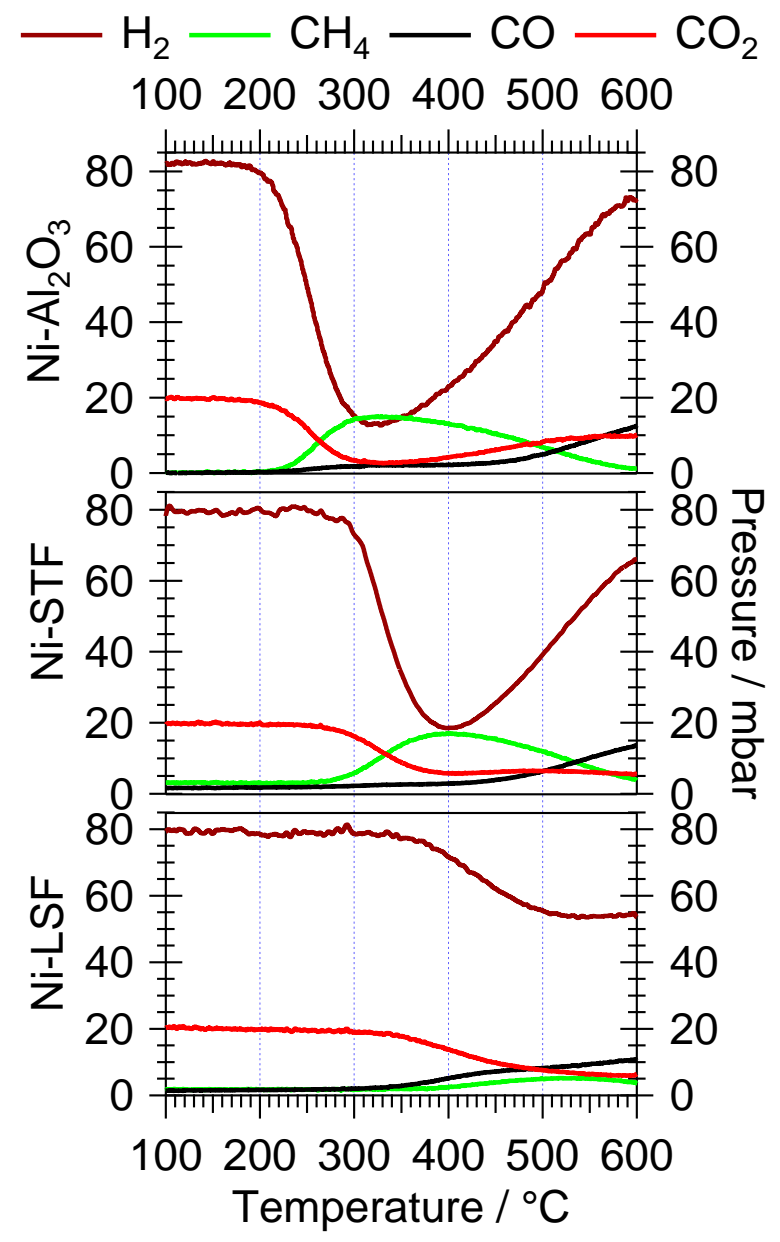

Figure S6: $\mathrm{CO}_{2}$ methanation reaction from $\mathrm{CO}_{2}\left(\mathrm{CO}_{2}+4 \mathrm{H}_{2} \rightarrow \mathrm{CH}_{4}+2 \mathrm{H}_{2} \mathrm{O}\right)$ on the Ni$\mathrm{Al}_{2} \mathrm{O}_{3}$ reference catalyst (upper panel) in comparison to the same reaction on Ni-STF (middle panel) and Ni-LSF (lower panel). Reaction conditions: 20 mbar $\mathrm{CO}_{2}, 80 \mathrm{mbar}_{2}$ and $25 \mathrm{mbar}$ $\mathrm{H}_{2} \mathrm{O}, 10$ mbar Ar, He added to 1 bar total pressure. Heating rate: $5^{\circ} \mathrm{C} \mathrm{min}^{-1}$. 


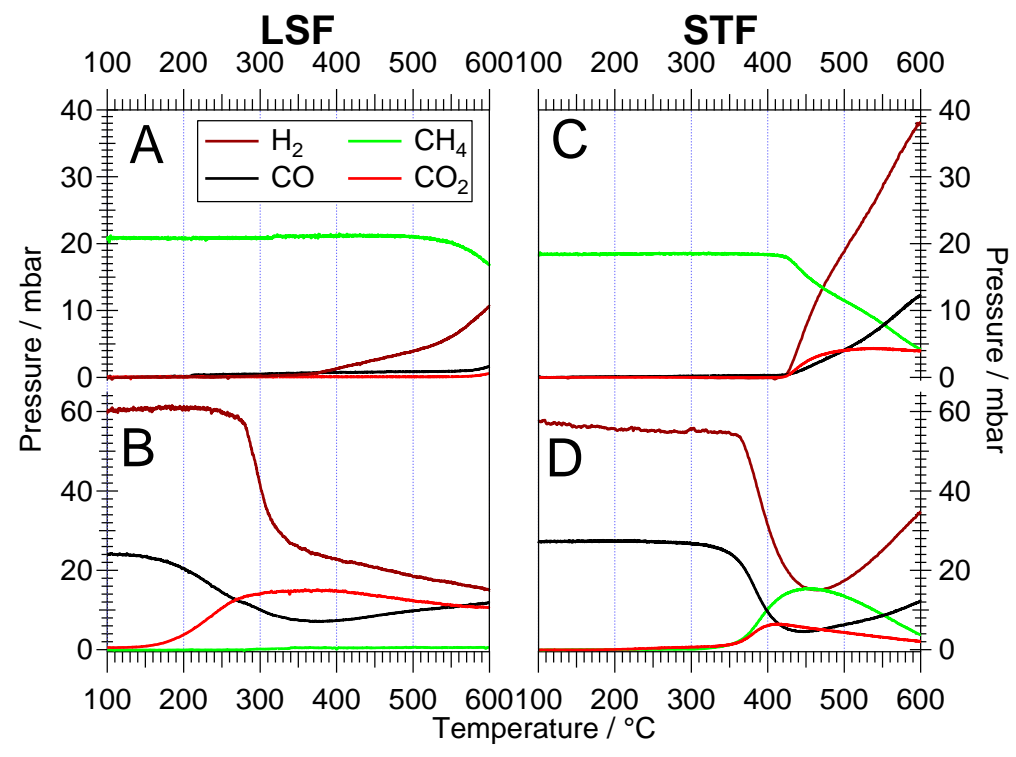

Figure S7: Methane steam reforming $\mathrm{CH}_{4}+x \mathrm{H}_{2} \mathrm{O} \rightarrow \mathrm{CO}_{x}+(2+x) \mathrm{H}_{2}$ (panel A and $\mathrm{C} ; 25$ mbar $\mathrm{H}_{2} \mathrm{O}$ and 25 mbar $\left.\mathrm{CH}_{4}\right)$, as well as $\mathrm{CO}$ methanation $\left(\mathrm{CO}+3 \mathrm{H}_{2} \rightarrow \mathrm{CH}_{4}+\mathrm{H}_{2} \mathrm{O}\right.$; panels B and D; 20 mbar CO, 60 mbar $\mathrm{H}_{2}$ ) on Ni-LSF (panels A-B) and Ni-STF (panels C-D). 10 mbar Ar added for correction of gas withdrawal, He added to 1 bar total pressure. Heating rate: 5 ${ }^{\circ} \mathrm{C} \min ^{-1}$. 

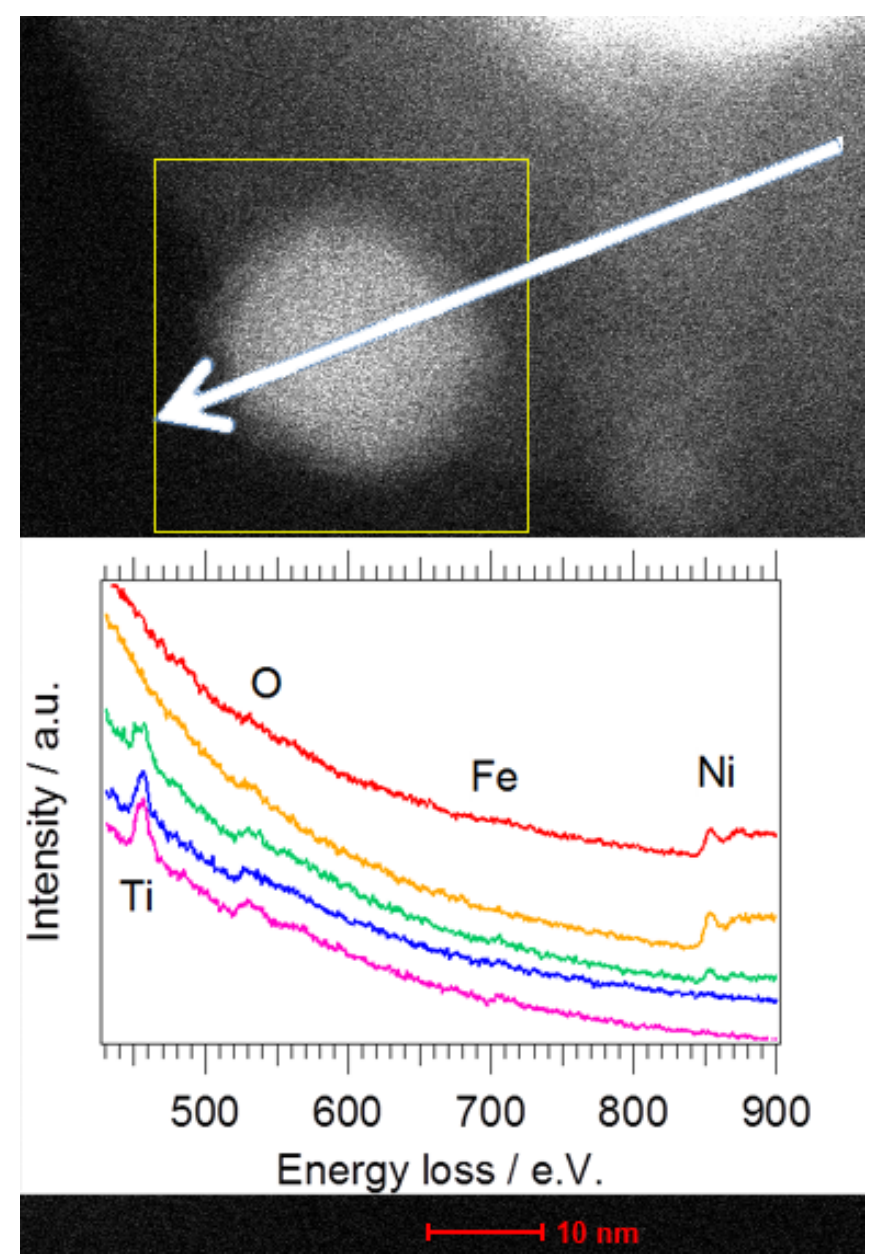

Figure S8: EELS linescans on Ni-STF after static reduction at $600{ }^{\circ} \mathrm{C}$ to exemplarily prove that at no point Fe particle exsolution has been found. 